\title{
BONE DEVELOPMENT AND ITS RELATION TO FRACTURE REPAIR. THE ROLE OF MESENCHYMAL OSTEOBLASTS AND SURFACE OSTEOBLASTS
}

\author{
Frederic Shapiro* \\ Department of Orthopaedic Surgery, Orthopaedic Research Laboratories, Children's Hospital Boston, Boston MA, \\ USA
}

\begin{abstract}
Bone development occurs by two mechanisms: intramembranous bone formation and endochondral bone formation. Bone tissue forms by eventual differentiation of osteoprogenitor cells into either mesenchymal osteoblasts (MOBL), which synthesize woven bone in random orientation, or surface osteoblasts (SOBL), which synthesize bone on surfaces in a well oriented lamellar array. Bone repair uses the same formation patterns as bone development but the specific mechanism of repair is determined by the biomechanical environment provided. Bone synthesis and maintenance are highly dependent on the blood supply of bone and on cell-cell communication via the lacunar-canalicular system. Recent investigations highlight the molecular cascades leading to cell differentiation, the components of the structural proteins such as the various collagens, and tissue vascularization. The patterning of bone matrix from an initial woven to an eventual lamellar orientation is essential for bone to develop its maximum strength. This review demonstrates the repetitive nature of woven to lamellar bone formation as mediated by MOBLs and SOBLs in both normal vertebrate bones and bone repair. Repair, using endochondral, primary, direct and distraction osteogenesis mechanisms, is reviewed along with the associated molecular, vascular, and biophysical features.
\end{abstract}

Key Words: bone development, fracture repair, osteotomy, intramembranous bone, endochondral bone, mesenchymal osteoblasts, surface osteoblasts, distraction osteogenesis.

*Address for correspondence:

F. Shapiro

Department of Orthopaedic Surgery

Orthopaedic Research Laboratories,

Children's Hospital Boston

Boston, MA 02115, USA

Telephone Number: 1-617-355-6753

FAX Number: 1-617-730-0236

E-mail: Frederic.Shapiro@childrens.harvard.edu
Introductory concepts and terms

\section{Bone formation}

Bone formation is complex but the three-dimensional positioning of cells and matrices is straightforward. As in any discussion of bone formation it is important to keep in mind the distinction between bone as a tissue (bone cells and the mineralized matrix) and bone as an organ (including several tissues such as bone, cartilage, fibrous tissue, marrow and blood vessels). Normal bone develops using only 2 mechanisms:

a) Intramembranous bone formation is mediated by the inner periosteal osteogenic layer with bone synthesized initially without the mediation of a cartilage phase.

b) Endochondral bone formation describes the synthesis of bone on a mineralized cartilage scaffold after epiphyseal and physeal cartilage have shaped and elongated the developing organ. These mechanisms are also used in fracture and osteotomy repair with the specific mechanism dependent on the mechanical environment provided during repair. With intramembranous bone repair, mesenchymal cells differentiate along a preosteoblast to osteoblast line while endochondral bone repair is characterized by the initial synthesis of cartilage followed by the endochondral sequence of bone formation. The terms intramembranous and endochondral refer to the tissue being replaced, not to the eventual bone synthesized which is the same in both mechanisms.

\section{Matrix orientation}

In bone tissue formation osteoblasts synthesize and deposit type I collagen, the main protein constituent of bone matrix, in only 2 basic conformations, $\boldsymbol{a}$ ) woven and $\boldsymbol{b}$ ) lamellar. In woven bone the collagen fibrils are randomly oriented while in lamellar bone they are clustered in parallel arrays. The fibrils in lamellar bone are not parallel to each other and to the longitudinal axis; rather they alternate in adjacent layers between longitudinal and transverse orientations is a so-called orthogonal pattern. These processes are repeated in normal bone development, in bone repair utilizing any of several mechanisms, and in several pathologic conditions.

\section{Osteoblasts}

We use a specific terminology for osteoblasts describing them as either a) mesenchymal osteoblasts (MOBL) or b) surface osteoblasts (SOBL) since these 2 variants only are seen to underlie essentially all bone tissue formation (Shapiro, 1988). Matrix conformation shift from woven to lamellar is virtually always abrupt with infrequent tendency to shading of one pattern into the other via fibroosseous or chondro-osseous accumulations. With the first 

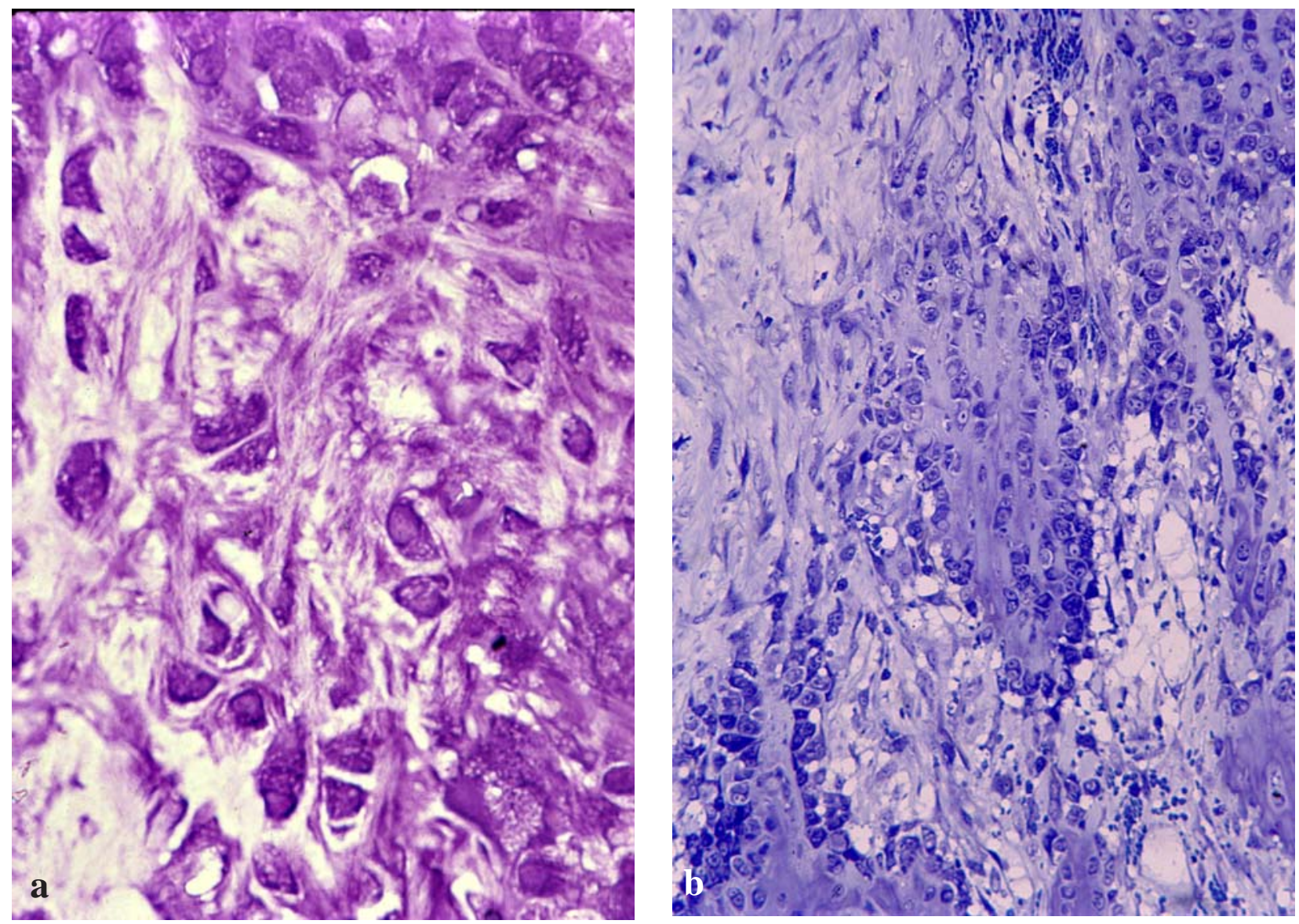

Figure 1. (a) Mesenchymal osteoblasts (MOBL) are illustrated. These cells are beginning to differentiate and are surrounded by a newly forming randomly oriented collagen matrix. The tissue illustrated is from the central part of a circular cortical femur defect in the rabbit at one week post-injury. (Toluidine blue stain, plastic embedded section). (b) Mesenchymal osteoblasts (MOBL) are now seen surrounded by a recognizable woven bone matrix from a site of distraction osteogenesis in a rabbit tibia. (Toluidine blue stain, plastic embedded section)

stages of bone formation, in an environment where no preexisting bone matrix is present, undifferentiated mesenchymal cells differentiate to pre-osteoblasts and then to osteoblasts that secrete collagen fibrils in a 360 degree direction in random pericellular array. We refer to these cells as mesenchymal osteoblasts and the bone matrix synthesized as woven (Fig. 1). When a sufficient amount of woven bone has been synthesized to serve as a structural scaffold, osteoblasts which we refer to as surface osteoblasts,: i) array themselves in well-polarized fashion only along the woven bone surface, ii) secrete collagen fibrils only onto the bone surface (not circumferentially), and iii) secrete fibrils in a parallel or lamellar orientation (Figs. 2, 3, 4). An osteoblast completely surrounded by the mineralized collagen matrix is now an osteocyte, although it can be in woven or lamellar bone. Both cell types secrete collagen molecules, which subsequently aggregate into fibrils in the extracellular matrix.

\section{Structural stages of bone formation. Overview of normal bone development}

A developing long bone consists of the epiphyses and metaphyses at each end and the diaphysis (shaft) in between. These regions are established by the middle of the embryonic stage and go through proportional changes in size until skeletal maturity (Figs. 5 and 6). The epiphyses are responsible for the transverse and spherical growth of the ends of the bone, the shaping of the articular surfaces, and the longitudinal growth of the metaphyses and the diaphysis. A small amount of longitudinal growth also occurs with interstitial expansion of the epiphyseal cartilage, including the undersurface of the articular cartilage. Each epiphysis, formed initially completely in cartilage, subsequently differentiates into three histologically distinct regions. These are: i) the cartilage at the outermost boundary of the epiphysis adjacent to the joint space that is the articular cartilage, ii) the cartilage adjacent to the metaphysis that forms the physis (growth plate, epiphyseal growth plate), and iii) the cartilage between the articular cartilage and the physeal cartilage referred to as the epiphyseal cartilage, which will form a secondary ossification center after vascular and osteoprogenitor cell invasion (Forriol and Shapiro, 2005; Rivas and Shapiro, 2002). The cells and matrices of the perichondrial ossification groove of Ranvier (the terminal extension of the periosteum) surrounding the physis and part of the metaphysis and are an integral part of longbone development (Shapiro et al., 1977). The groove is first evident at stage 6 of development (Fig. 5) and in all subsequent stages until skeletal maturity (Figs. 5, 6). 
Table 1. Histologic stages in long bone and epiphyseal development

\author{
Stage* Histologic events \\ Stage 1 Limb bud formation, uniform distribution of mesenchymal cells, and formation of apical ectodermal ridge \\ Stage 2 Mesenchymal condensation \\ Stage 3 Cartilage differentiation \\ Stage $3 \mathrm{a} \quad$ Interzone formation \\ Stage $3 b \quad$ Chondrocyte hypertrophy in middle part of long bone cartilage mode \\ Stage $4 \quad$ Epiphyseal shaping \\ Stage 4a Formation of intramembranous periosteal bone at mid-diaphysis (primary center of ossification) \\ Stage $5 \quad$ Resorption of joint interzone and formation of smooth articular cartilage surface \\ Stage 5a Vascular invasion of hypertrophic chondrocyte area, endochondral bone formation (mid-diaphysis), and completion \\ of formation of primary centre of ossification \\ Stage $6 \quad$ Formation of the physis and of peripheral perichondrial groove tissue \\ Stage 6a Farthest relative extent of epiphyseal/physeal position \\ Stage $7 \quad$ Epiphyseal cartilage vascularization with formation of cartilage canals \\ Stage 8 Central chondrocyte hypertrophy to form spherical mass, development of growth plate completely surrounding \\ secondary ossification centre \\ Stage 9 Vascular invasion of developing secondary ossification centre into hypertrophic chondrocytes adjacent to mineralized \\ cartilage matrix \\ Stage 10 Bone formation and marrow cavitation in secondary ossification centre, formation of hematopoietic marrow \\ Stage $11 \quad$ Increase in size of secondary ossification centre at relative expense of epiphyseal cartilage \\ Stage 12 Central chondrocyte hypertrophy and secondary ossification centre growth plate changed from spherical to \\ hemispherical orientation \\ Stage 13 Fat in marrow, hematopoietic marrow adjacent to secondary ossification centre growth plate \\ Stage 13a Epiphyseal bone plate formation \\ Stage 14 Fullest relative extent of secondary ossification centre development in epiphyseal cartilage \\ Stage 15 Thinning of growth plate \\ Stage 15a Involution of secondary ossification centre growth plate \\ Stage $15 \mathrm{~b} \quad$ Subchondral bone plate formation \\ Stage 16 Resorption of growth plate with linkage of epiphyseal and metaphyseal circulations \\ Stage 16a Calcification of lowest zone of articular cartilage, tidemark formation, transformation of all marrow to fat
}

*The substages labeled a and $\mathrm{b}$ refer to events occurring at the same time as a particular stage in different parts of the same bone or to a structurally important continuation of the same process at a slightly later time. (From Rivas and Shapiro, 2002)

The growth plate components go through a sequential process of cell proliferation, synthesis of extracellular matrix, cell hypertrophy, mineralization of the matrix, localized vascular invasion accompanied by osteoprogenitor cells, and apoptosis. These highly coordinated activities lead to longitudinal bone growth and bone formation at the physeal-metaphyseal region and encompass the mechanism of endochondral ossification. The growth cartilage replenishes itself through the germinal zone and continually is replaced with bone at the physealmetaphyseal junction (Fig. 7). With these coordinated events the length of the entire bone increases, the physes at either end are displaced progressively further away from the centre of the bone, and the physis itself maintains the same height throughout the growth period. At the same time, there is radial growth of the diaphysis and parts of the metaphysis by intramembranous bone formation with direct apposition of cortical bone by osteoblasts from the inner cambial layer of the periosteum (Fig. 8). This is coordinated closely with resorption of bone by osteoclasts on the inner cortical endosteal surfaces and lateral metaphyseal surfaces to maintain the relative proportions of the marrow cavity to the cortices and the overall shape of the bone as it grows. We have outlined 16 stages with several additional substages of long bone and epiphyseal development to show the timing and coordination of the growth process (Table 1 and Figs. 5 and 6). The endochondral and intramembranous ossification sequences are involved together not only in long bone formation but also in formation of the pelvis, vertebrae, sternum, ribs, scapula and clavicle. Skull and facial bone formation and repair are similar but have slight differences owing to origin from differing embryonic lines and are outside the scope of this review.

\section{The blood supply of bone}

Bone is a well-vascularized tissue and organ. The periosteal circulation supplies the periosteum, the surrounding muscles and the outer $1 / 3$-rd of the underlying cortex. The bone marrow and inner 2/3-rds of the cortex are supplied by the medullary circulation, which originates from the nutrient arteries, which enter the bone through specific nutrient foramina and then branch within the marrow cavity towards each end of the diaphyseal bone. There are considerable intracortical anastomoses between the inner medullary and outer periosteal vessels (Rhinelander, 1968; Trueta and Morgan, 1960). During the development of long bones the epiphyseal cartilage 


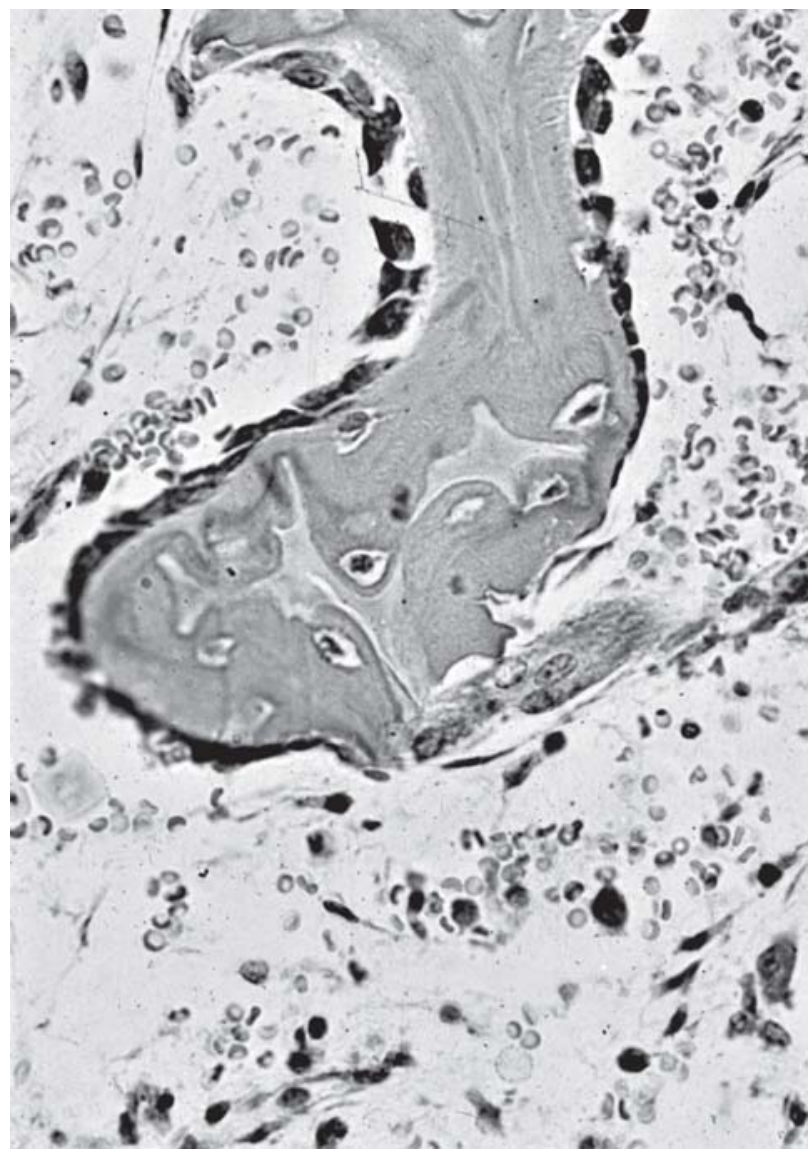

Figure 2. Surface osteoblasts (SOBL) are aligned on a metaphyseal trabecula from newborn bovine bone. Remnants of cartilage are noted surrounded by bone containing osteocytes in lacunae. An osteoclast is seen at lower right of the trabecula. (Hematoxylin and eosin stain, paraffin embedded section)

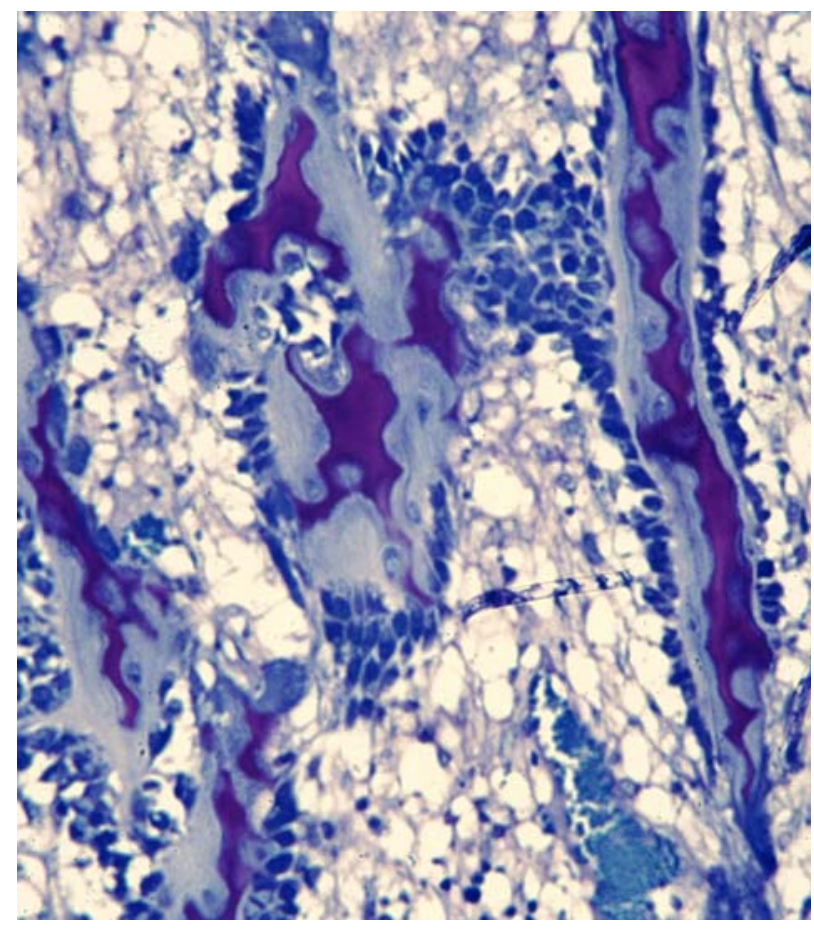

Figure 3. Surface osteoblasts (SOBL) are seen in newborn rabbit metaphyseal bone aligned on the surface of bone trabeculae. The newly synthesized bone is light blue and the dark purple staining material within each trabecula is the persisting calcified cartilage. (Toluidine blue stain, plastic embedded section)

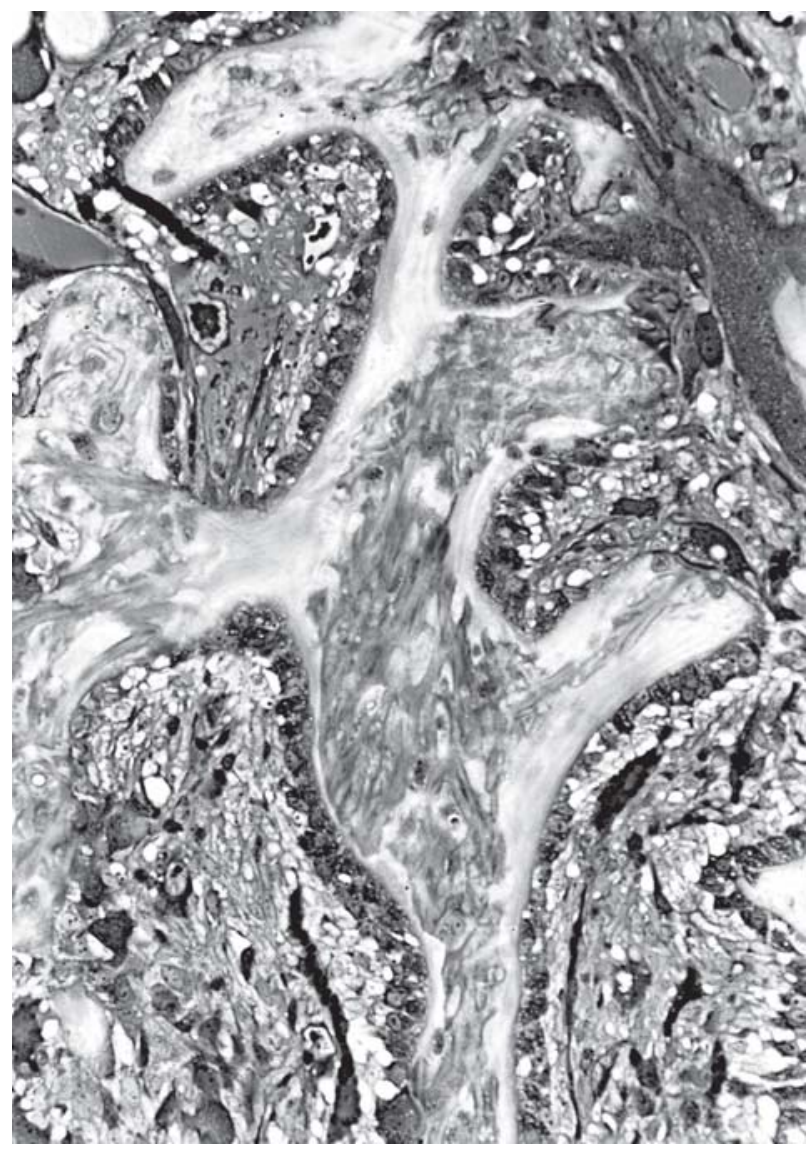

Figure 4. Surface osteoblasts (SOBL) line the surface of bone repair tissue from a circular cortical rabbit femur defect at 2 weeks. Initially synthesized woven bone has been surrounded by lighter staining lamellar bone with surface osteoblasts clearly seen. (Toluidine blue stain, plastic embedded section)

receives nutrition from vessels in the cartilage canals, which also provide a source of osteoprogenitor cells for the secondary ossification centres (Haines, 1933; Shapiro, 1998). The articular cartilage is never vascularized, receiving nutrition by diffusion from the synovial fluid, and the physes are also avascular except for the presence of transphyseal vessels in the foetal period and early postnatal months. The physis has a dual blood supply although the vessel systems are totally separate from one another. The resting, proliferating, and upper hypertrophic layers are supplied by diffusion via epiphyseal vessels [E-vessels] above while the metaphyseal vessels [M-vessels] below enter the lower hypertrophic region only and provide osteoprogenitor cells to synthesize bone on the calcified cartilage cores (Dale and Harris, 1958). The metaphyseal vessels are the terminal ramifications of the medullary circulation within the marrow.

Cell-cell communication in bone via the lacunarcanalicular system and gap junctions

Light microscopic sections of bone show the osteocytes to be present in round to oval shaped spaces in the bone referred to as lacunae, which are linked to adjacent lacunae by multiple small canals referred to as canaliculi (Burger and Klein-Nuland, 1999; Palumbo et al., 1990a; Palumbo et al., 1990b; Ribinacci et al., 2002; Shapiro, 1988; 

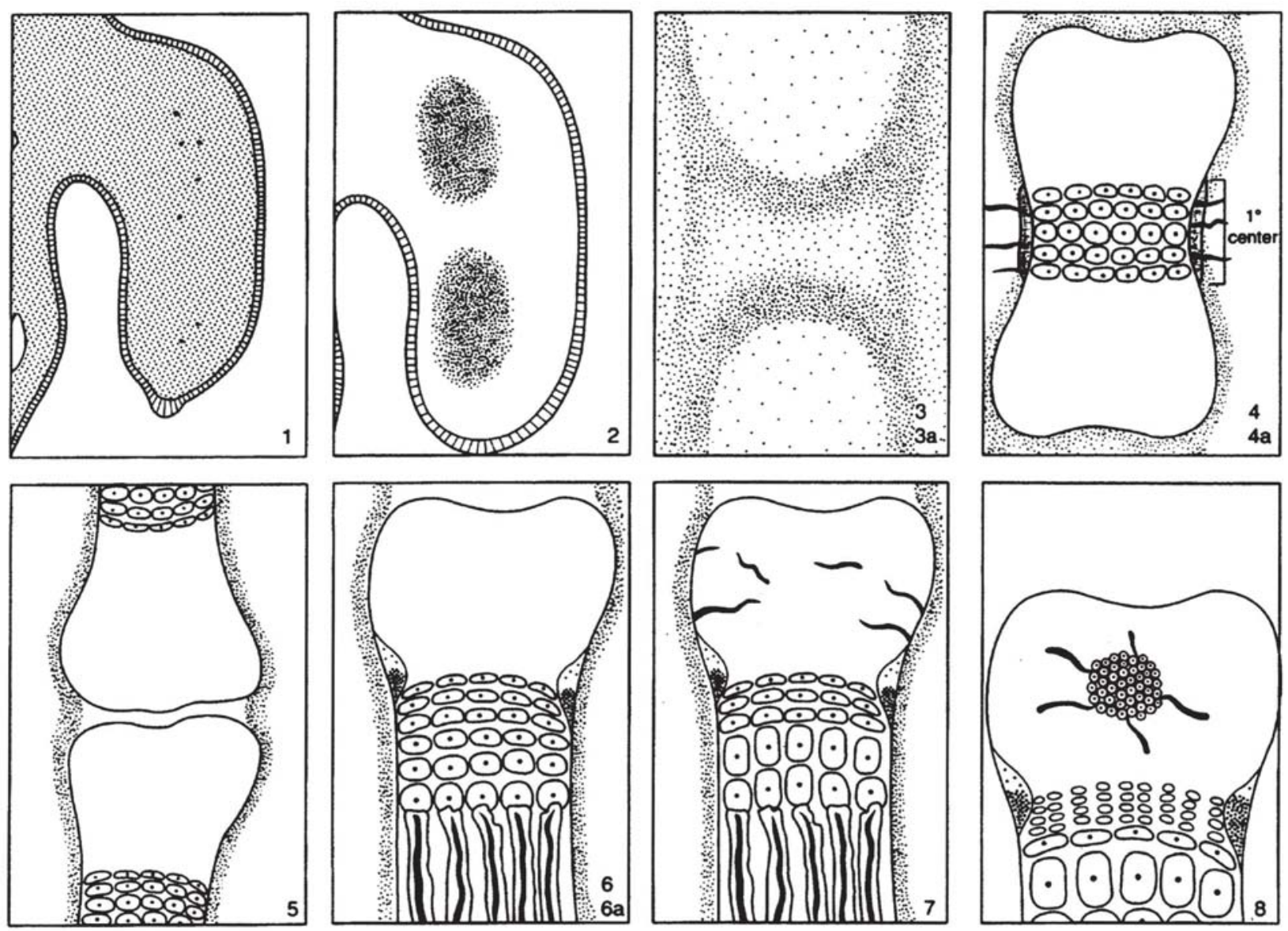

Figure 5. Stages 1 to 8 in the formation and development of long bones and epiphyses are illustrated. The stage is numbered at lower right in each panel. Refer to Table 1 for detailed descriptions.

Shapiro, 1997). The lacunae house the osteocytes and the canaliculi contain the osteocyte cell processes. The lacunarcanalicular intraosseous system plays a key role in the transfer of nutritive fluid from blood vessels to bone cells. The common technique used for assessing bone by light microscopy involves haematoxylin and eosin staining of paraffin embedded sections. This technique does not demonstrate the lacunar-canalicular system well, and frequently scarcely shows it all. Plastic embedded, toluidine blue-stained sections outline well the organized lacunar-canalicular system in cortical bone (Fig. 9) (Shapiro, 1988). The canaliculi link osteocytes and blood vessels extensively. A canaliculus passes into or away from a lacuna by a mean distance of $1.9 \mu \mathrm{m}$ over the entire osteocyte perimeter (Shapiro, 1988). Undifferentiated mesenchymal cells have no processes, as seen by transmission electron microscopy, but soon sprout a florid array of processes as differentiation to early mesenchymal osteoblasts proceeds. Osteoblast and osteocyte cell processes are packed with actin $(7 \mathrm{~nm}$.) and intermediate filaments $(10-11 \mathrm{~nm}$.) including vimentin that are continuous with those in the cell bodies (Fig. 10) (Shapiro et al., 1995). Intercellular gap junctions are seen between surface osteoblasts, between osteoblasts and underlying osteocytes, and between osteocyte cell processes in the canaliculi (Fig. 11). The woven bone canaliculi pass into the matrix in irregular, poorly defined pathways, but once lamellar bone is formed, the canaliculi assume a more regular orientation passing between osteocytes either perpendicular or parallel to the longitudinal bone axis.

\section{Biophysical effects underlying bone development, maintenance, and repair}

The mechanical effects on normal and abnormal bone have been recognized since the nineteenth century but experimental studies are now allowing for molecular and biophysical (Borgens, 1984) understanding. The intercellular communication system of bone, mediated through the lacunar-canalicular system, allows for biophysical control mechanisms essential to tissue development and maintenance. In a work primarily relating to bone as a tissue, it was indicated how mechanotransduction (the conversion of a biophysical force into a cellular response) encompasses four distinct steps: mechanocoupling, where mechanical loads cause bone deformations that stretch/compress cells and create fluid movement within canaliculi; biochemical coupling, mediated by force transduction through the integrincytoskeleton-nuclear matrix structure (cell as mechanosensor); transmission of biochemical signal, via surface osteoblasts and lining endothelial cells reacting to cyclic mechanical bending or osteoblasts/osteocytes communicating via gap junctions linking cell process to adjacent cell process and transmitting small messenger molecules or electric signals; and an effector cell response where the effects of the former 3 features direct or inhibit 

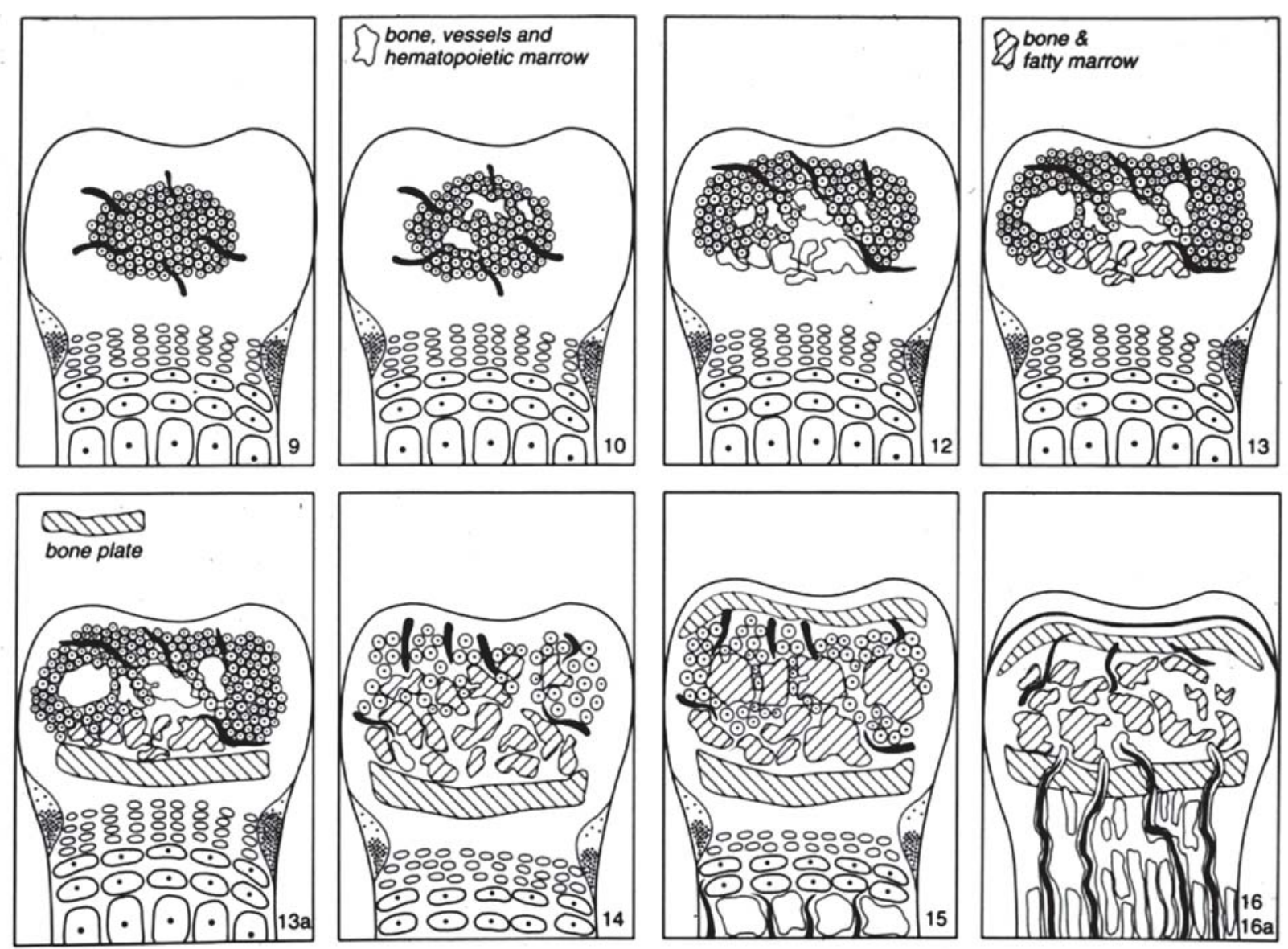

Figure 6. Stages 9 to 16 in the formation and development of long bones and epiphyses are illustrated. The stage is numbered at lower right in each panel. Refer to Table 1 for detailed descriptions.

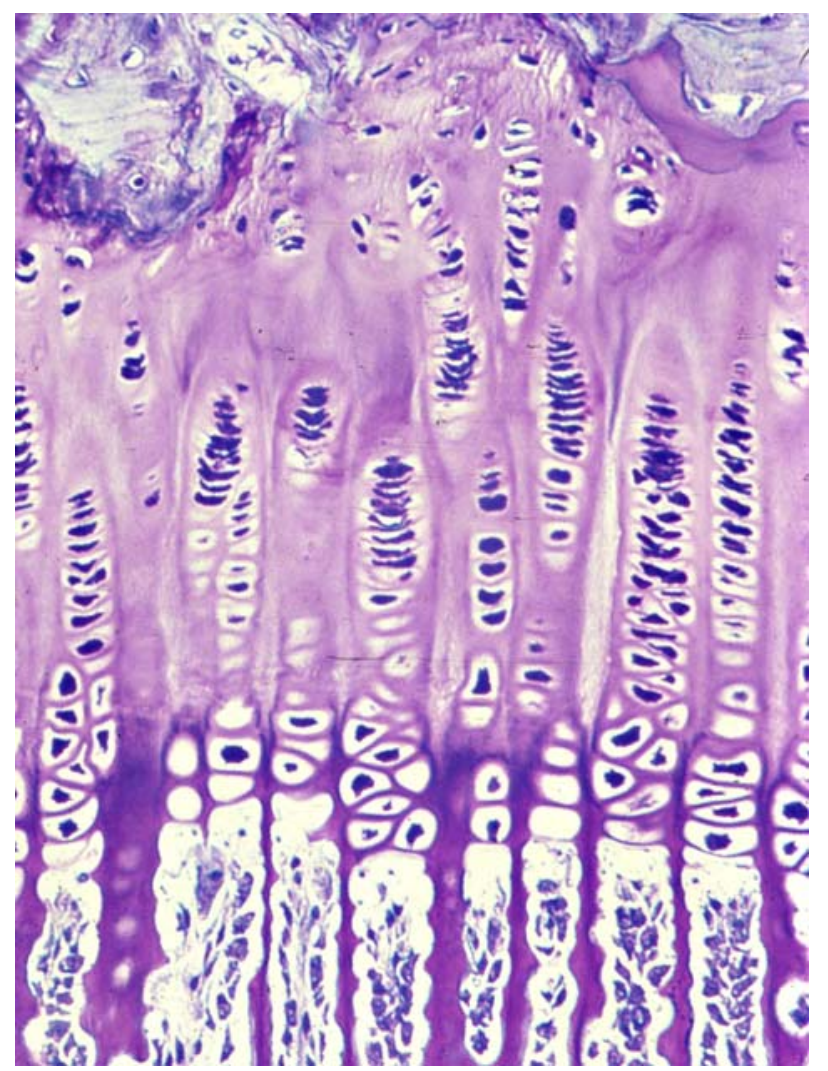

Figure 7. Proximal tibial physis from a one-month-old rabbit is shown. Epiphyseal bone is seen above and metaphyseal bone below the growth cartilage plate. (Toluidine blue stain, plastic embedded section) the cell response (Duncan and Turner, 1995). Bone cells in a physiologic strain range have an equal balance of bone formation and bone resorption. Decreased strain (disuse) favours resorption over formation, increased (but still physiologic) strain favors formation over resorption whereas massively increased strain (pathologic) leads to structurally less effective woven bone formation.

The biophysical effects in limb morphogenesis on mesenchymal tissue, including muscle and cartilage, have been assessed (Henderson and Carter, 2002). The combined cellular activity of the growth process generates deformations and pressures caused by the developing tissue itself, which influences morphogenesis by modulating growth rates, modulating tissue differentiation, influencing the direction of growth, or deforming tissues. A target cell responds in four basic ways to incoming signals by: direct contact from a touching cell or from extracellular matrix, diffusible molecules that bind with surface receptors or intracellular molecules, gap junctions between adjacent cells, or imposed tensions and pressures wherein growth generated strains and pressures from the mechanical environment induce the target cells into specific synthetic functions. Studies on cultured osteoblasts allow for quantitative assessments of applied strains that alter matrix synthesis (Forriol and Shapiro, 2005).

The mechanical principles controlling the internal architecture of bone were assessed in detail in the last half of the $19^{\text {th }}$ century by many authors and codified by Wolff 


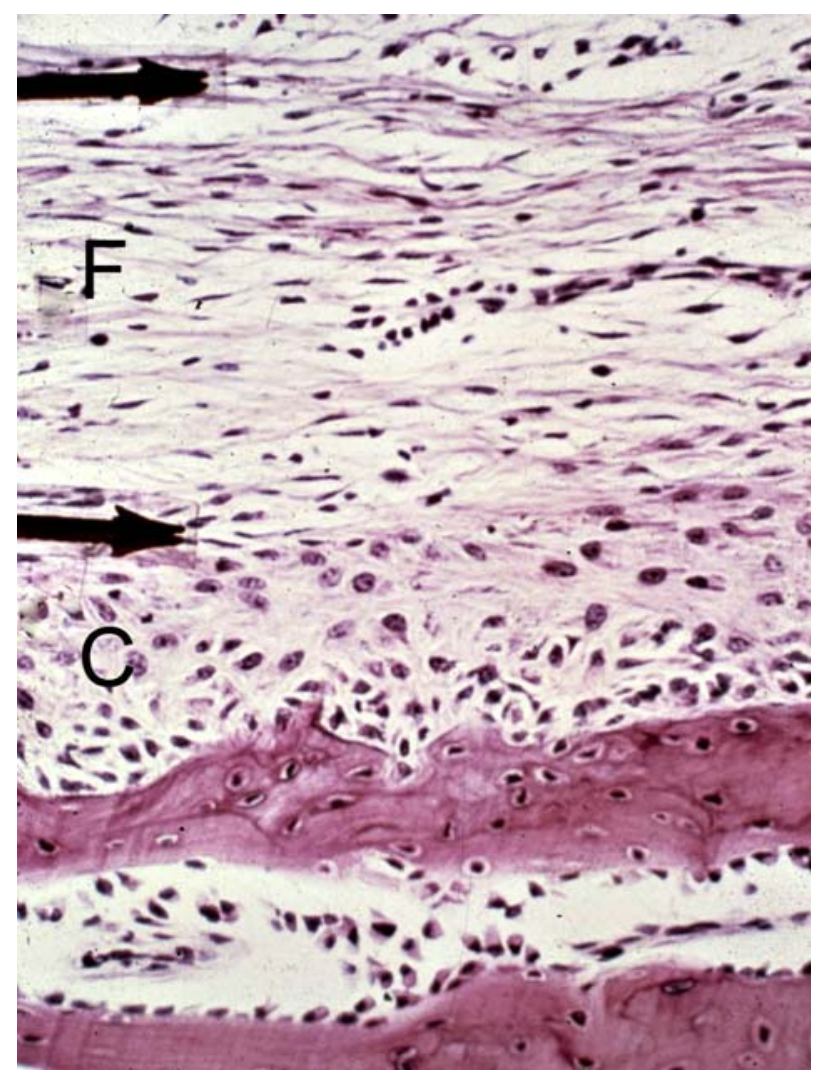

Figure 8. Periosteum and adjacent cortical bone from the newborn rabbit femur are illustrated. The outer fibrous layer $(\mathrm{F})$ and the inner cambial osteogenic layer (C) of the periosteum are shown. Newly formed bone is shown at bottom. At lower left lamellar bone with surface osteoblasts covers initially synthesized woven bone. (Haematoxylin and eosin stain, paraffin embedded section)

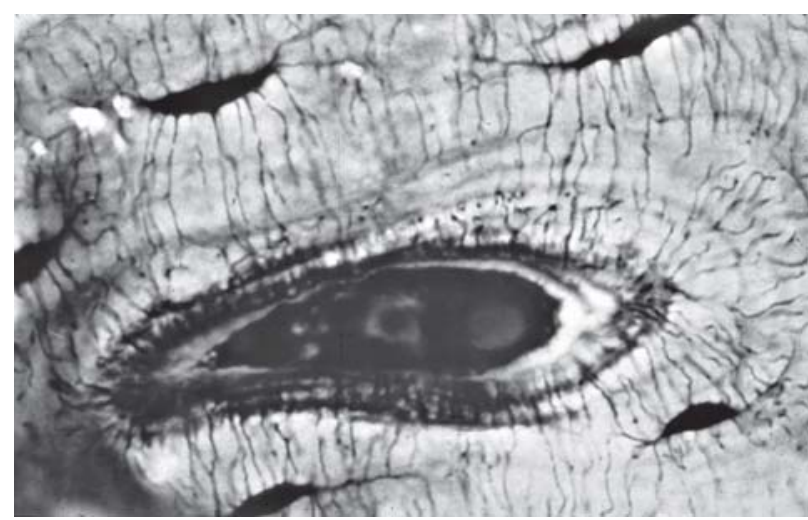

Figure 9. Photomicrograph, from repair femoral cortical bone 4 weeks following creation of a $2.4 \mathrm{~mm}$ defect in the rabbit, shows a central blood vessel and surrounding osteocytes in lacunae. Heavily stained toluidine blue section illustrates the canaliculi connecting adjacent osteocytes and osteocytes to the central Haversian canal.
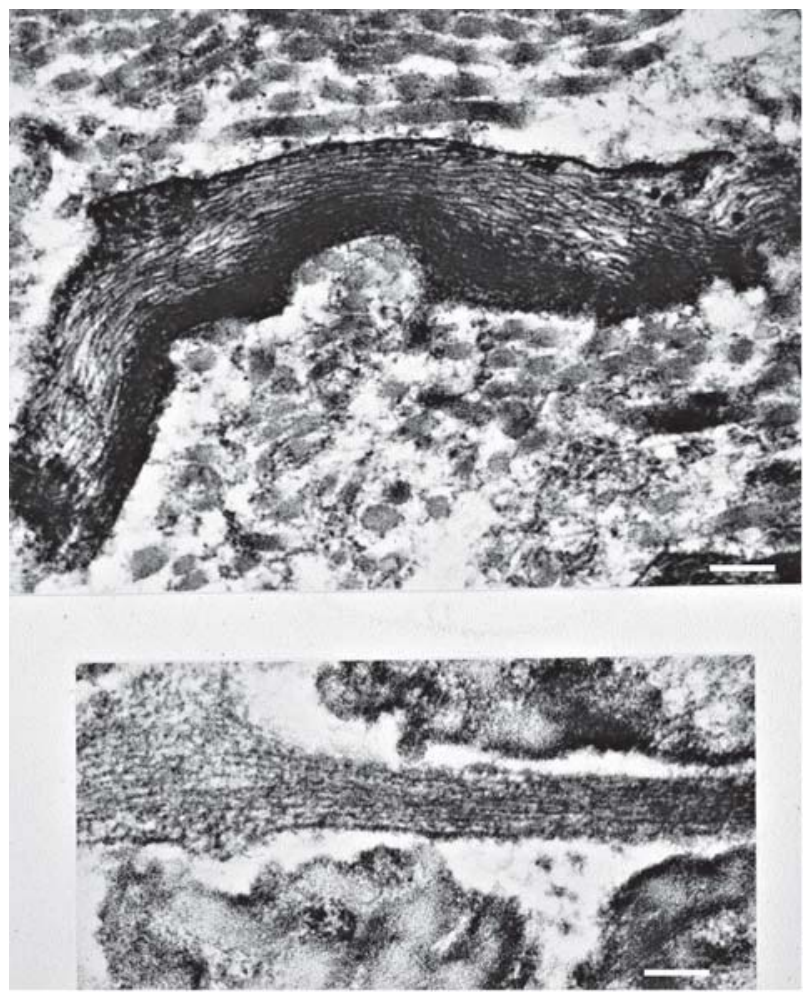

Figure 10. Transmission electron micrographs show rabbit femur osteoblast process in osteoid (above) (Scale bar: 190nm) and osteocyte process in bone (below) (Scale bar: 140nm). Both processes contain intracellular filaments.

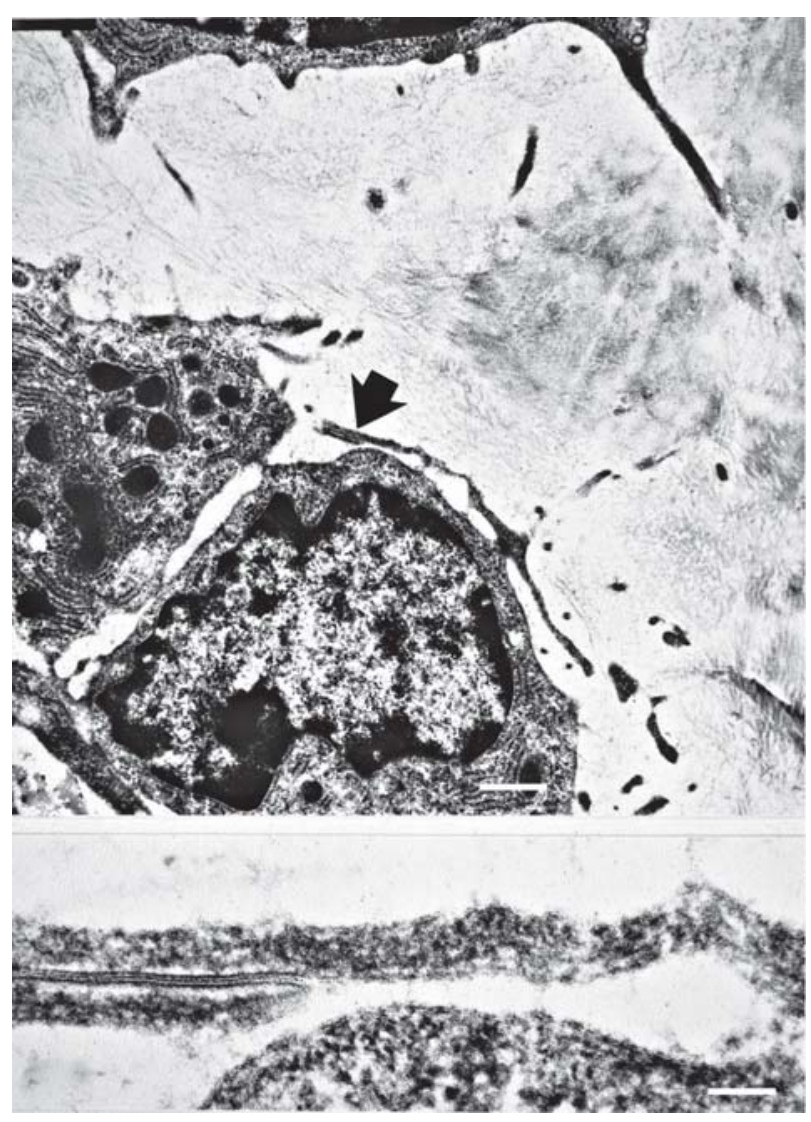

Figure 11. Transmission electron micrographs show osteoblast processes in rabbit femoral bone with gap junction (arrow) (Scale bar: 500nm) above and higher power view of gap junction below (Scale bar: 100nm). 
in his classic "Das Gesetz der Tranformation der Knochen" (Wolff, 1892) [translated into English as "The Law of Bone Remodelling" (1986)]. In these works the trabeculae of bone were considered to be arranged for appropriate structural support along the lines of pressure and tension trajectories. There was early awareness however that mechanical principles operated to guide differentiation of mesenchymal tissues into bone, cartilage or fibrous tissue. Roux (1912) felt that undifferentiated tissues would respond differently in terms of developing connective tissue phenotype depending on whether they were exposed to tension, shear or compression. Krompecher (1937) related cell response to the specific mechanical environment provided. He stressed that mechanical factors were involved with bone formation in normal development (Krompecher, 1934) and with fracture repair (Krompecher, 1956). Moderate tension forces applied to fractures caused intramembranous bone rather than cartilage formation. $\mathrm{He}$ demonstrated direct bone formation from fibrous tissue (desmoid tissue) in the presence of blood vessels, a mechanism he contrasted with endochondral bone formation, and referred to as primary angiogenic bone formation (primäre angiogene Knochenbildung).

Pauwels considered that there were only two different types of mechanical stimuli that influenced differentiation of mesenchymal cells. These stimuli caused either pure distortion of shape by stretch or pure change of volume by hydrostatic pressure. The nature of the stress determined the cell differentiation pathway. Distortion of shape was due to stretch, which led to collagen fibril production whether the stretching arose from compression (external and unequal), tension or shear stress. The nature of the deformation (shape change) was dependent on the plane of change as the force was applied. The collagen fibril production in tension led to fibrous tissue, which could then differentiate to intramembranous bone while compression, led to cartilage formation, which could then differentiate to endochondral bone. In his conception bone could only form from cells protected from intermittent stretching by either the fibrous tissue or cartilage. Change of volume was due to hydrostatic pressure, which produced uniform (equal throughout) and extreme stress within the cell whether applied externally or internally. Hydrostatic pressure (compression) caused cells to differentiate into cartilage. He recognized that shear caused a change in cell shape and stimulated fibroblast formation whereas hydrostatic compression which changed cell volume but not shape stimulated chondrocyte formation; when these two forces were combined in a tissue area the combined stress favoured mixed tissue formation such as fibrocartilage. In his mechanical construct, soft tissues were necessary in repair to stabilize the mechanical environment and only when this happened could bone formation occur (Pauwels, 1976 [English translation]; Weinans and Prendergast, 1996).

Understanding which mechanical force leads to what tissue type remains a matter of intense investigation. Stress is a general term defined as force exerted between contiguous bodies and strain is a slightly more specific term referring to a pull or a stretching force that tends to counteract the stability of a structure or region. There are three forces of differing types that eventually translate into tissue differentiation to different specific phentotypes. i) Tension refers to a state of being pulled or stretched tight; a tensile force serves to stretch or draw out an object or region. ii) Compression refers to a state of being squeezed together to occupy less space. Hydrostatic (often referring to compression) defines the pressure exerted by liquids at rest. iii) Shear refers to a state produced by pressure such that each layer slides over the next; a shear force distorts or breaks a structure usually by an oblique or rotatory force. There is general agreement today that tensile stress leads to intramembranous ossification; compression favours chondrocyte formation: constant hydrostatic compression leads to cartilage formation while intermittent compression favours actual endochondral ossification; and high shear stresses favour fibrous tissue formation (Carter et al., 1998). These descriptions refer to primarily uniaxial forces but in reality many forces on developing or repairing bones are multiplanar. Pauwels developed the concept of mixed forces, recognizing that the combination of shear and hydrostatic compression led to fibrocartilage formation. Cyclic motion and shear tend to a large external callus production.

Claes and colleagues have quantified the magnitudes of the hydrostatic pressure and strain that select either the intramembranous or endochondral sequences. By analysis of experimental callus geometry they determined that if compressive hydrostatic pressure (negative) exceeded 0.15 $\mathrm{MPa}$ endochondral bone formation occurred whereas if hydrostatic pressure was below this threshold intramembranous bone formed (Claes and Heigele, 1999). Perren has focused attention on the interfragmentary repair tissues themselves, developing the interfragmentary strain (IFS) theory that the fracture gap could only be filled with a tissue capable of sustaining IF strain without rupture. If IFS is high, only fibrous granulation tissue can form; if it is intermediate, cartilage is present and when low, bone formation follows. The formation of a large soft tissue callus stabilizes the gap peripherally, decreasing motion, decreasing IFS and allowing progressive tissue differentiation from fibrous to cartilaginous to bone. The elongation potential of granulation tissue was considered to be $+100 \%$, cartilage $+10 \%$ and bone only $2 \%$.

Awareness is increasing that the mechanical effects on tissue differentiation are mediated at the individual cell level and that the cells respond to cell level deformations and to fluid flow. Fluid flow can cause mechanical stimuli within tissues at the cell level by further increasing cell deformation. Bone cells (osteocytes) communicate with each other, with overlying osteoblasts and with cells lining intraosseous vessels via the lacunar-canalicular system. Consideration is growing that tissues should be analyzed as solid-fluid mixtures. Owan et al. (1997) have gone so far as to consider that responsiveness to fluid flow may be more important than mechanical strain in bone cells. Prendergast and van der Meulen (2001) point out that biomechanical stress on cells is high if fluid flow is high and that both matrix deformation and fluid flow taken together define the mechanical milieu of the cell. 
In summary, for intermittently imposed loading in repair tissues: i) direct intramembranous bone formation occurs in areas of low stress and strain, ii) hydrostatic compressive stress is a stimulus for chondrogenesis, iii) high tensile strain is a stimulus for the net production of fibrous tissue, and iv) tensile strain with a superimposed hydrostatic compressive stress will stimulate the development of fibrocartilage.

Bone was recognized as generating intrinsic bioelectric potentials in the 1960s (Bassett and Becker, 1962; Friedenberg and Brighton, 1966). Efforts were made to harness this phenomenon to hasten bone repair by applying either alternating pulsed electromagnetic fields or lower power direct current to fracture sites (Bassett et al., 1964; Bassett et al., 1982; Brighton, 1981). These methods along with low intensity pulsed ultrasound, extracorporeal shock wave stimulation, and low intensity high frequency vibration, are less frequently used today but the phenomena and the differing ways of application remain attractive for future investigation (Chao and Inoue, 2003).

\section{The molecular biology of developing bone and of fracture repair}

Since the histologic appearance of repair bone is the same as that associated with various phases of normal bone and cartilage tissue development it stands to reason that the molecular involvement (Barnes et al., 1999; Einhorn, 1998 ) is at least similar and in most ways probably the same. Several reports have outlined this similarity (Ferguson et al., 1999; Gerstenfeld et al., 2003; Vortkamp et al., 1998). Repair bone shows the same array of i) structural proteins (such as type I collagen in bone and types II and X collagen in repair cartilage callus and hypertrophic chondrocytes respectively) and ii) the many regulators of chemotaxis, mitosis and differentiation such as wnt, Indian hedgehog (ihh), downstream genes responding to hedgehog proteins like Gli 1 and patched (Ptc), bone morphogenetic proteins (BMP 2, BMP 3 [osteogenin], BMP 4, and BMP 7 [osteogenetic protein, OP 1]), Smads 1-8 (a class of proteins that function as intracellular signaling effectors for the TGF- $\beta$ superfamily), the transcription factor core binding factor 1 (cbfa 1) stimulating osteoblast differentiation, fibroblast growth factors (FGF1, 2), platelet derived growth factors (PDGF), transforming growth factor beta (TGF- $\beta$ ) superfamily including matrix metalloproteinases (MMPs), and angiogenic molecules vascular endothelial growth factor (VEGF $\mathrm{a} \rightarrow \mathrm{d}$ ). At the start of the repair cycle, inflammatory cells secrete cytokines including (interleukin) IL-1, IL-2, RANKL and tumour necrosis factor (TNF $\mathrm{x}$ and $\mathrm{b}$ ).

The value of such studies lies in helping determine: i) why bone is one of the few organs that can fully repair itself (under the best circumstances) to a normal pre-injury structure and function, ii) how these molecules interrelate with one another and with the mechanical-biophysical environment to bring about bone tissue synthesis, and iii) which molecules are the main determinants for repair such that their use as pharmacologic agents can enhance repair. Amongst the molecules used clinically to enhance repair are recombinant human bone morphogenetic protein-2 (rhBMP-2) while experimental uses of vascular endothelial growth factor (VEGF), rhBMP 7 (OP1), transforming growth factor beta (TGF- $\beta$ ), platelet derived growth factor (PDGF), parathyroid hormone, and other molecules are being assessed in many laboratories (Gerstenfeld et al., 2003).

\section{Bone repair}

Bone repair can occur by different specific mechanisms primarily dependent on the biophysical environment. Although the various types of repair use differing normal cells and tissues, the eventual bone synthesis is always mediated by the mesenchymal and/or surface osteoblasts (MOBL and SOBL) and via the woven and/or lamellar matrix conformations. The histologic patterns of bone repair are: i) endochondral bone repair (repair by callus formation), mediated by inner periosteal layer and marrow tissues, synthesizing cartilage and then woven and lamellar bone in an environment of interfragmentary space and mobility; ii) primary bone repair (direct contact repair), mediated exclusively by intraosseous Haversian system osteoblasts (SOBL) and osteoclasts, without a cartilage phase, in which osteoclasts (in cutting cones) resorb necrotic bone on either side of the fracture or osteotomy, followed by the osteoblasts synthesizing lamellar bone initially parallel to the longitudinal axis of the bone such that no remodelling of the repair bone is needed, in an environment of no interfragmentary space and rigid stability; iii) direct bone repair (gap repair, direct transformational bone repair) mediated also without a cartilage phase by marrow derived vessels and mesenchymal cells, initially perpendicular to the long axis of the bone (woven and lamellar) in an environment of interfragmentary space $>0.1 \mathrm{~mm}$ with rigid stability and then remodelled along the long axis; and iv) distraction osteogenesis (callotasis) mediated by inner layer periosteal and marrow (including endosteal) tissue, synthesizing woven and then lamellar bone in the slowly widening gap, parallel to the long axis of the bone in an environment of more or less stability and slow distraction.

Bone repair must also be considered in relation to the regions of bone where repair is occurring, for example: cortical (diaphyseal) fractures in dense compact bone and metaphyseal or epiphyseal fractures occurring in the spongiosa where bone trabeculae are distributed within marrow spaces.

The source of repair cells following a fracture or osteotomy of bone can be from i) the inner osteogenic layer of the periosteum, ii) the osteoprogenitor cells associated with the blood vessels of the Haversian systems within the cortical bone, iii) the endosteal cells (endosteum) lining the inner cortex, iv) the undifferentiated mesenchymal cells of the bone marrow, and v) (according to some) the "soft tissue" undifferentiated cells of the surrounding muscle and connective tissue based on their ability to differentiate as needed. The environment provided for repair determines which source of cells serves as the primary repair agent. In endochondral bone repair with motion between the fragments the periosteum is the 


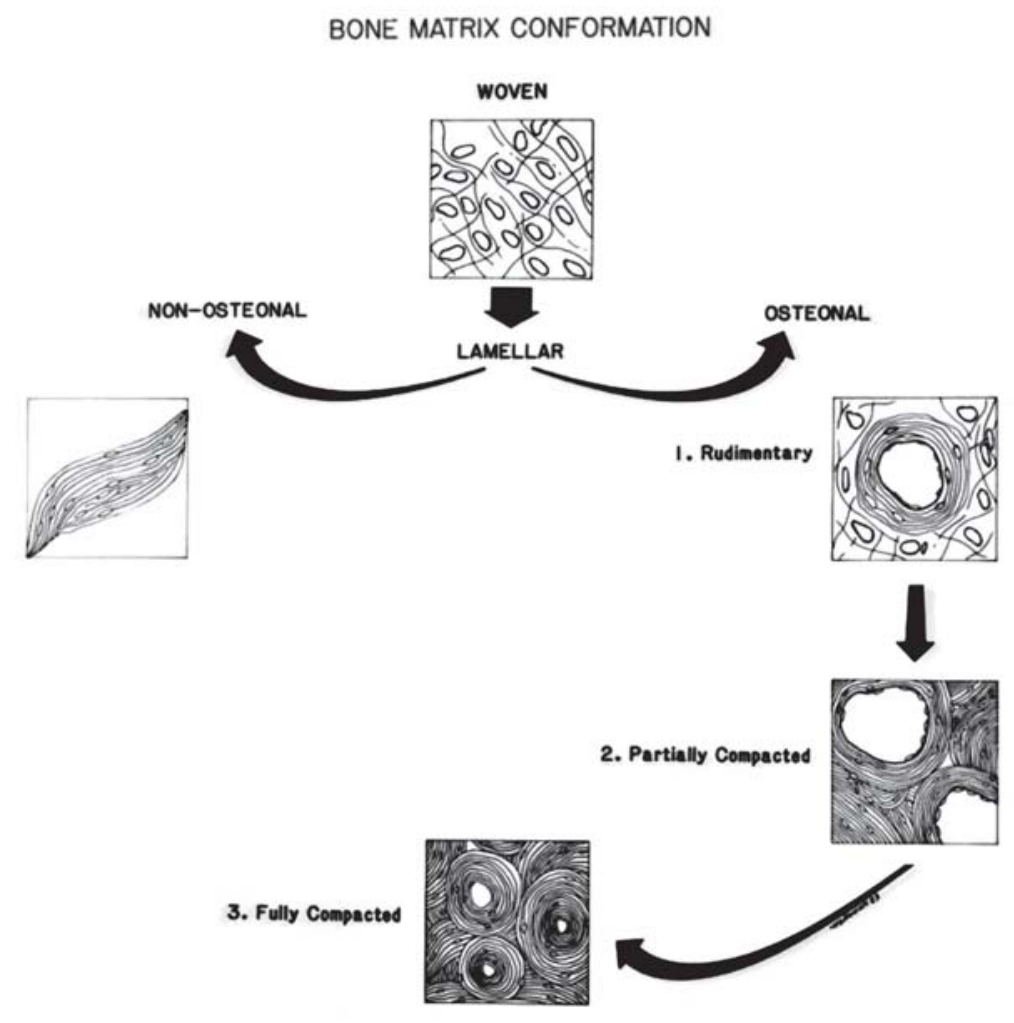

Figure 12. Bone matrix synthesis, both in normal development and fracture or osteotomy repair, generally begins with woven bone synthesis followed by lamellar bone synthesis once the woven scaffold is in place. Osteonal bone, forming around central Haversian blood vessels which are generally aligned along the long axis of the bone, begins as rudimentary or primary osteons and progresses by lamellar compaction to partially compacted and then fully compacted bone. This occurs as surface osteoblasts synthesize lamellar bone first on woven bone surfaces and then build up tissue deposition circumferentially around and towards the central vessel. Lamellar bone forms also in metaphyseal regions but is non-osteonal in nature.

main source of repair cells. With rigid internal fixation and anatomic coaptation of fragments with a gap of less than $0.1 \mathrm{~mm}$, the repair is exclusively from the intracortical vessel-associated osteoprogenitor cells and with direct bone repair with rigid fixation but a gap of greater than $0.1 \mathrm{~mm}$ the marrow stem cells are the primary repair source moving into the interfragmentary gap.

\section{Discussion of specific structural features of bone development and repair}

\section{Woven bone and lamellar bone}

Bone formation is initiated with matrix deposition in a randomly oriented pattern referred to as woven or coarse fibred bone followed by its replacement with bone with a definitive lamellar structure (Figure 12). There are several patterns of lamellar bone deposition in vertebrates described as: i) uniform lamellae encircling the entire diameter of the bone, ii) a more complex pattern characterized by laminae separated from adjacent structures by vascular canals, or iii) multiple Haversian systems or osteones such as occur in higher mammals including humans (Foote, 1916). A Haversian system or osteon in cortical bone refers to a central canal containing longitudinally oriented vessels and associated osteoprogenitor cells surrounded by concentric lamellae of bone matrix. Many Haversian systems are present in a cross-section of cortical bone. Longitudinally oriented lacunae containing osteocytes are embedded in the lamellae and link both adjacent cells and osteoblasts accompanying the blood vessels. Canaliculi containing the osteocyte cell processes extend to and from the lacunae.

The formation, structure and continuous remodelling of the bone matrices have been the subject of detailed investigation with various works defining: coarse-fibred primary bone and fine-fibred lamellar bone (Jaffe, 1929); woven-fibred bone, parallel-fibred bone and lamellar bone (Weidenreich, 1930); and woven-fibred bone, primary osteones, secondary osteones, surface bone, and interstitial bone (Smith, 1960a; Smith, 1960b). The mechanisms by which regions of woven bone are subsequently found to be composed of dense lamellar bone are of considerable biological and clinical importance. Woven bone in the human is seen characteristically in association with bone formation: i) in the foetus and newborn, ii) in initial early repair following fractures and osteotomies, and iii) in pathologic states as diverse as osteogenesis imperfecta and osteopetrosis.

Woven bone is synthesized by differentiating mesenchymal cells, which we refer to as mesenchymal osteoblasts (MOBL), which have just differentiated along 
a pre-osteoblast to osteoblast line in a localized region where no bone is present. It has a matrix with randomly oriented collagen and is relatively hypercellular with round to oval cells linked by cell processes in canaliculi, which are also randomly oriented. It is weak structurally and is synthesized primarily to serve as a scaffold upon which the better oriented and mechanically stronger lamellar bone is deposited. Once a sufficient amount of woven bone has been deposited to serve as a scaffold, osteoblasts, which we refer to as surface osteoblasts (SOBL), align in single array along the woven bone surface and deposit new matrix in a linear or lamellar orientation.

Lamellar bone is less cellular than woven bone, its osteocytes are flattened and aligned along the long axis of the respective lamellae in the matrix, and the canaliculi are more regularly patterned parallel and perpendicular to the osteocytes and adjacent blood vessels. The lamellae in secondary (remodelled) bone align in multilayered cylindrical osteons around a central blood vessel.

The distinction between woven and lamellar bone can usually be made by unmodified light microscopy especially when the two types are closely apposed (Fig. 4). Definitive distinction is made however by polarized light microscopy using two polarizing lenses inserted between the light source and the histology slide on a rotating stage (Modis, 1991). A polarizing lens allows passage of light in only one plane. Woven bone does not allow light to pass throughout a complete 360 degree rotation of the specimen since there is always a random organization of the collagen fibrils regardless of the rotation of the specimen. The woven bone is said to be isotropic owing to the random orientation of the collagen which does not influence the polarization of light. The parallel alignment of collagen fibrils in lamellar bone allows the bone to transmit polarized light at certain degrees of rotation of the two polarizers. When the polarizers are in the same plane as the lamellae, which occurs at certain degrees of rotation, bright light is transmitted. Lamellar bone is said to be anisotropic because the properties of the oriented collagen fibrils are different in different directions, which allows transmission of light through the oriented polarizers in one plane and no transmission at right angles to it.

The lamellae of cortical bone are not all in the same plane however. The early works of Gebhardt (1905) and Petersen (1930) demonstrated well the structural organization of the collagen fibres in mature bone. Thin and thick lamellae alternate and adjacent sheets are positioned at oblique angles to one another in what is referred to as a "twisted plywood" orientation (GiraudGuille, 1988) for structural support. The angles between adjacent arrays in lamellar bone have been studied (Weidenreich, 1930) and it was shown that most angles were 30 degrees with a subset at 70 degrees (Weiner et al., 1997). They proposed a structural model for collagen organization with an individual lamellar unit (thick and thin lamellae) composed of 5 arrays of parallel fibrils each offset by 30 degrees. The spiral twisting of fibre orientation in bone lamellae has been assessed by others as well (Wagermaier et al., 2006, Weidenreich, 1930). Another feature of collagen fibril orientation in lamellae is that it is a self-assembly process in the organic extracellular matrix determined to a large extent by local stress-strain conditions and by the intrinsic chemical properties of the collagen molecules rather than being specifically cell-directed (Bouligand et al., 1985; Cisneros et al., 2006; Kadler et al., 1996).

\section{Endochondral bone repair}

Endochondral bone repair describes bone repair which occurs in an initial environment of macromotion and then micromotion between the fragments such as with fractures treated in a cast or with traction. After injury there is extensive bleeding with tearing of the periosteum and adjacent soft tissues. A large haematoma contained by the surrounding tissues forms after which a fibrinous blood clot is formed to serve as a medium for repair cell ingrowth. The first few days post-fracture are characterized by an inflammatory phase. It is now considered that molecules associated with the inflammatory phase and blood clot formation are essential for initiating the correct repair response. The outer fibrous layer of the periosteum eventually reconstitutes to contain the haematoma and clot while the inner cambial layer undergoes intense proliferation and differentiation to initiate and carry out repair. Some observers feel that adjacent undifferentiated mesenchymal soft tissue cells from injured connective tissue including even muscle, tendon, and fascia also participate in repair by induction along the cartilage/bone lines. Bone repair begins from the periphery of the cortex, several centimetres away from the fracture site, as the inner layer of the elevated periosteum lays down intramembranous woven bone against the cortex in a stable and still well vascularized part of the repair site. Closer towards the fracture however the relative movement of the repair environment and the relative tissue hypoxia due to damage to the blood supply leads to the formation by the inner periosteum and undifferentiated mesenchymal cells of a large cartilaginous mass both outside the cortices, external callus, and within the cortices, internal callus. The callus that is initially cartilaginous and fibrocartilaginous serves to stabilize the fracture site, an action which then favours bone formation. Vascularity advances in the increasingly stable environment deeper into the callus from the periphery of the cortex furthest away from the facture site and from the reconstituted periosteum at the outer margin of the external callus. In doing so woven bone is relatively rapidly synthesized on calcified cartilage cores of the callus until the repair cartilage has been converted completely to bone by the endochondral mechanism. This further stabilizes the fracture site. The next stage of the repair process involves transforming the woven bone to lamellar bone, resorbing the external callus which is no longer needed since the fracture ends have been bridged and stabilized by healing tissue, and remodelling the Haversian cortical bone to lie along the longitudinal axis. This process of healing is referred to as endochondral bone repair since the synthesis of cartilage to bridge the fracture ends eventually repeats the same mechanism for bone formation used at the growth plate, namely chondrocyte hypertrophy, cartilage matrix 


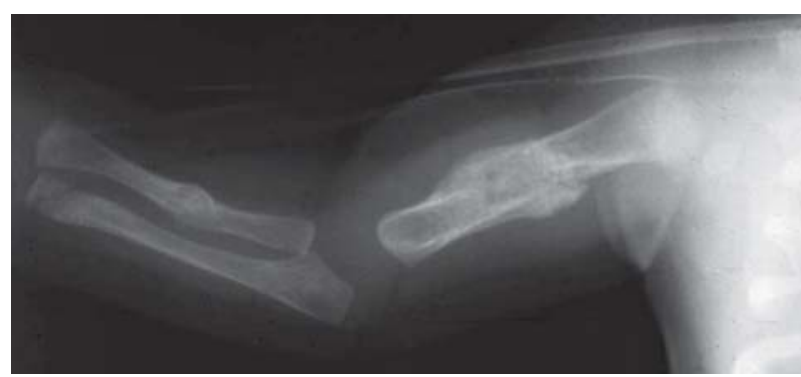

Figure 13. Radiograph of a displaced mid-diaphyseal humeral fracture illustrates endochondral bone repair with callus at 3 weeks post-injury in a patient with osteogenesis imperfecta. Note the more advanced healing of previous radius and distal ulna fractures.

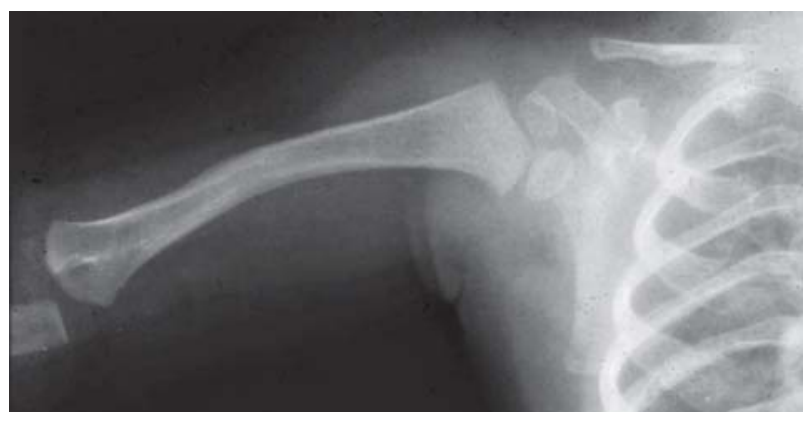

Figure 14. Radiograph of the same humerus shown in figure 13 at one year post injury showing complete repair with excellent remodelling. calcification, invasion of hypertrophic chondrocyte lacunae by osteoprogenitor cells and blood vessels, and bone tissue formation on the calcified cartilage cores. The term endochondral simply refers to the tissue replaced in forming the definitive bone tissue since the bone formed eventually has the same structure and molecular composition as bone formed by other mechanisms (Figs. 13 and 14).

The description of bone healing using this mechanism was understood in basic outline in the 1700 s and was clearly outlined by Dupuytren (1847), long before the era of histologic or radiographic assessment. The histologic criteria have been extensively assessed over the past century and many papers outlining the process continue to warrant attention (Cornil and Coudray, 1904; Koch, 1924; McKibbin, 1978; Wehner, 1921). The descriptions and illustrations of endochondral bone repair by Urist and Johnson (1941), Ham and Harris (1971) and Ham (1979) are particularly detailed.

Key features of the endochondral repair mechanism are illustrated in sections from a healing mid-femoral shaft fracture in the rabbit (Figs. 15 to 27). Even in this model of repair which is seemingly structurally diverse, we can see the biophysical principles directing bone repair to be operative. Intramembranous bone forms initially on the outer cortex at the most peripheral but also most stable and best vascularized region of the repair site. Once the cartilaginous callus stabilizes the fracture site, vascularization moves inward from the periphery and endochondral bone repair occurs. This is initially woven and mediated by mesenchymal osteoblasts (MOBL) but once there is sufficient woven matrix, surface osteoblasts (SOBL) synthesize lamellar bone on the woven bone cores. The lamellar bone then progresses towards the Haversian conformation encircling and closing in on vessels. The final stage in this repair process involves the resorption of extracortical bone and remodelling of cortical bone to lamellae parallel to the longitudinal axis.

\section{Bone repair terminology in rigid stable environments (primary and direct)}

When a stable environment for repair is established by early surgical fixation of the fragments the need for a large external cartilage callus is bypassed. With very rigid fixation the entire endochondral sequence can be bypassed and bone can form without callus and indeed without the interposition of cartilage tissue at all. Features of the repair environment however will still dictate the nature of the bone repair including the type and orientation of the synthesized bone matrices. When bone is formed without the mediation of a cartilage phase in anatomically reduced and rigidly stabilized fractures or osteotomies radiographs show repair bone to be deposited within the cortices and perhaps the marrow cavity with no external callus and no, or virtually no, periosteal elevation. The terminology used to describe these mechanisms of repair needs to be defined since different groups use similar terms in slightly dissimilar ways. Many will use the terms primary and direct bone repair interchangeably to indicate bone repair without the radiologic appearance of any periosteal new bone reaction or external callus. In this review we define primary bone repair as repair which occurs strictly within the cortex in situations where fractures or osteotomies are rigidly compressed in anatomic fashion with no interfragmentary gap causing repair to occur with initial lamellar bone deposition already parallel to the long axis of the bone by osteoprogenitor cells within Haversian canals or osteoclast cutting cones (Fig. 28). This is also referred to as contact repair (Perren et al., 1969; Perren, 1979; Schenk and Willenegger, 1964). We define direct bone repair as repair which occurs in situations where fractures or osteotomies undergo rigid surgical fixation but leaving an interfragmentary gap greater than $0.1 \mathrm{~mm}$ such that repair can occur without cartilage mediation but the bone formed originates from marrow cells and is aligned at right angles to the long axis of the bone such that it must subsequently undergo remodelling to align lamellar bone along the longitudinal axis. This is also referred to as gap repair (Perren, 1979) or direct transformational bone repair (Shapiro, 1988). The term direct transformational bone repair uses "direct", since there is no mediation of a cartilage phase with bone tissue formed initially, and "transformational" since initial woven bone synthesis is soon modelled to a lamellar conformation at right angles to the longitudinal axis, and then remodelled again to a lamellar conformation parallel to the longitudinal axis. Where this mechanism of bone repair occurs it appears that lamellar bone (perpendicular to the long axis, can be 


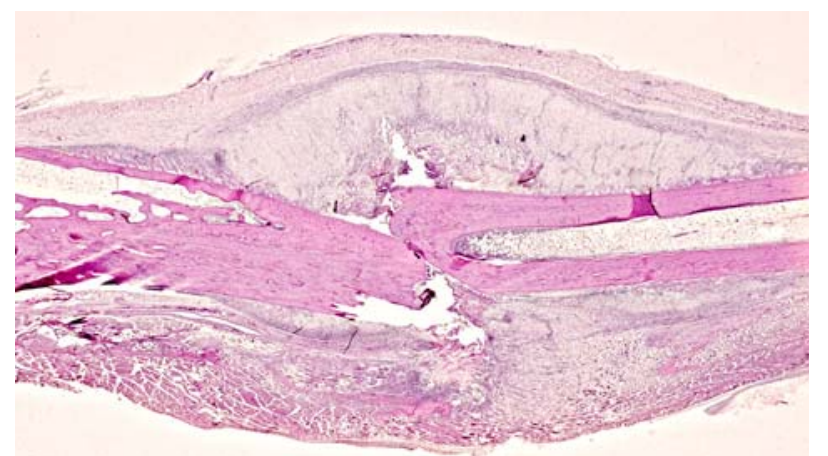

Figure 15. Longitudinal section of healing middiaphyseal fracture at one week in rabbit femur shows the early stage of endochondral bone formation. There is external and internal callus. At the upper portion the repair is cartilaginous and the fibrous layer of the periosteum has been reconstituted.

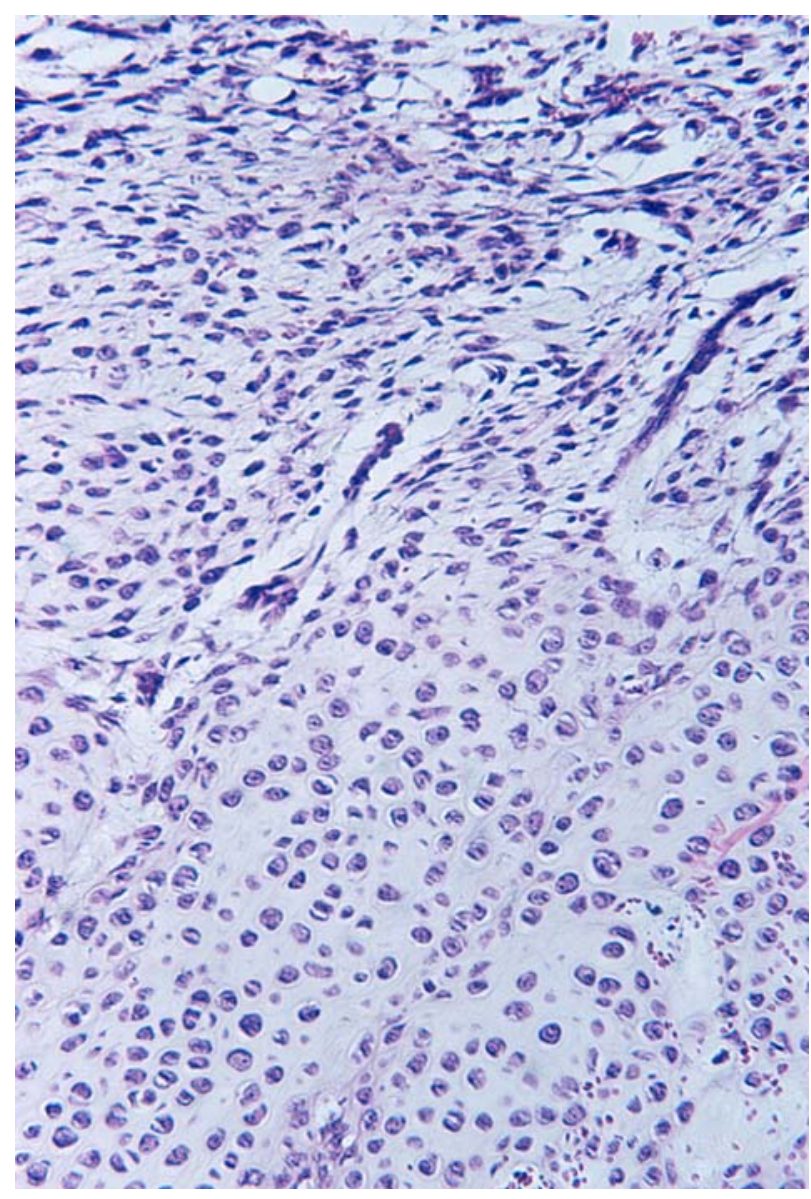

Figure 16. Higher power view of figure 15 shows the upper portion of the external callus at the level of the fracture. The overlying fibrous tissue is seen at top and early repair cartilage (at bottom).

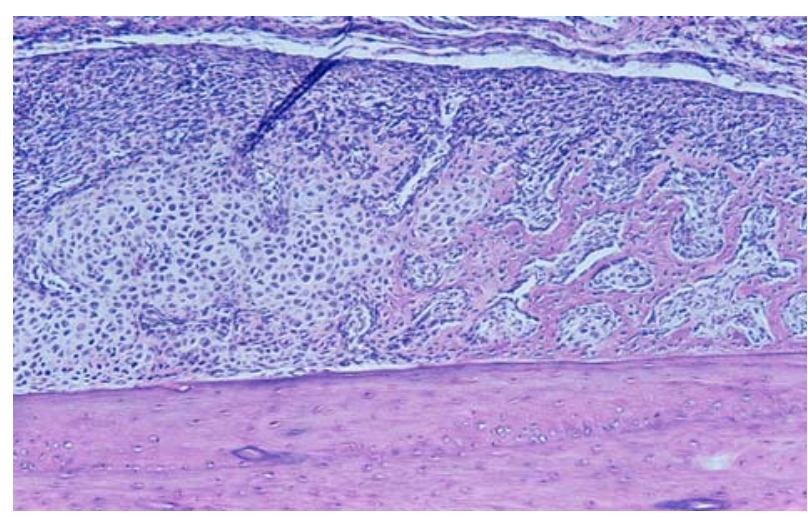

Figure 17. Higher power view of figure 15 at the far right region of repair (upper cortex) at one week shows the periosteal new bone formation against cortex at right but cartilage formation against cortex at left closer to the more mobile and less well stabilized fracture site.

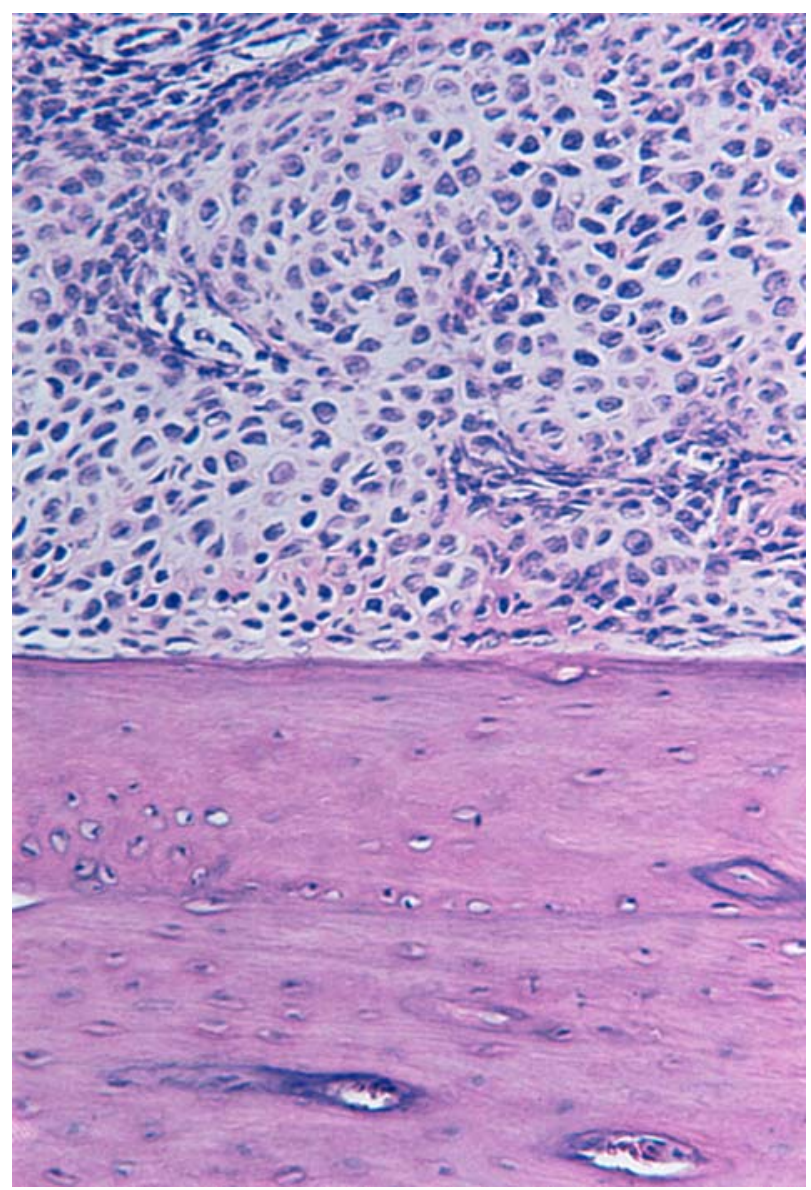

Figure 18. Higher power view of the central part of figure 17 shows cartilage tissue against persisting cortex at one week but also early traces of woven bone as vascularization and periosteal bone are increasingly synthesized from the periphery to the central region adjacent to the fracture site.

Figures 15-27. Photomicrographs illustrate progressive changes with endochondral bone repair in a rabbit middiaphyseal femur fracture. Varying levels of magnification illustrate structural features. All sections are paraffin embedded and stained with haematoxylin and eosin. 


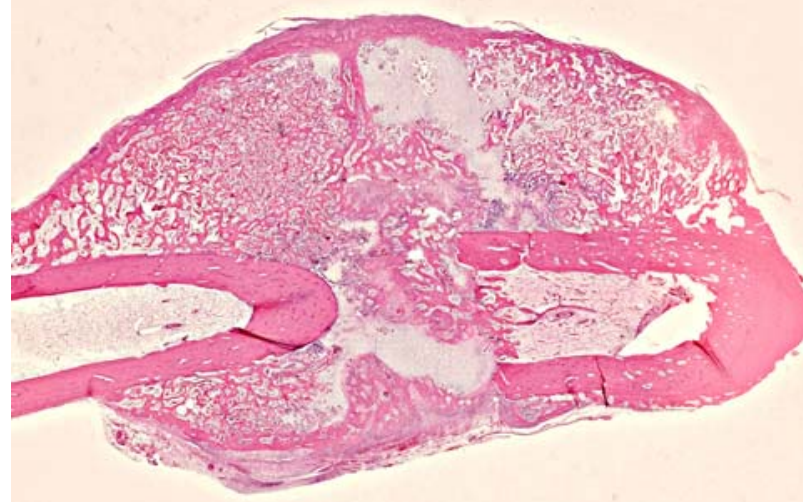

Figure 19. Photograph at 5 weeks illustrates both abundant bony callus with membranous bone formation along with endochondral repair in the rabbit femur. Newly synthesized bone has replaced the cartilage mass using the endochondral mechanism.

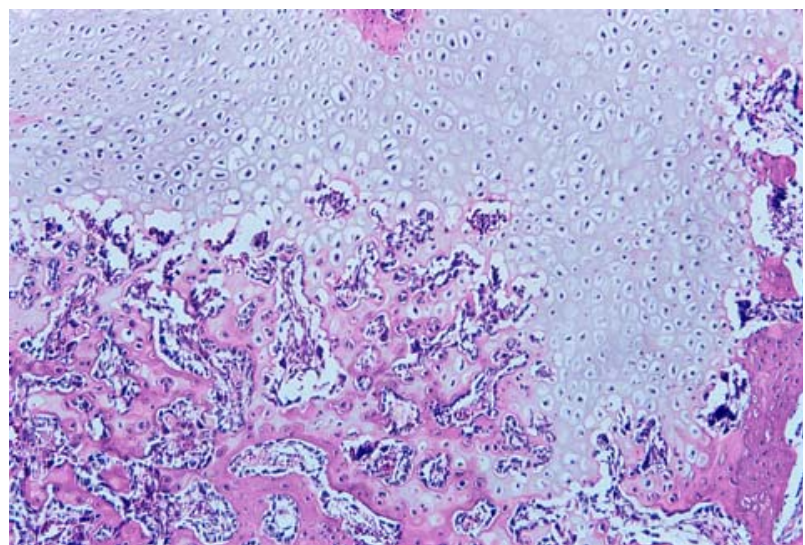

Figure 20. Higher power view of figure 19 shows persisting cartilage from external callus above with vascular invasion of the cartilage associated with classic endochondral bone formation on cartilage cores.

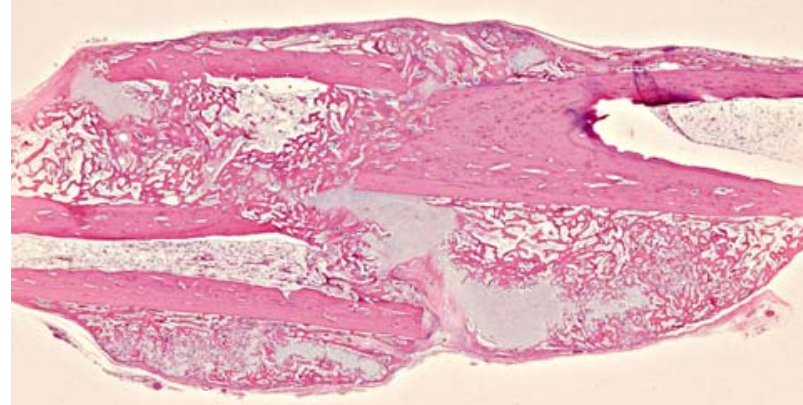

Figure 21. Endochondral repair in the rabbit femur at 6 weeks is shown. There is relatively little cartilage of the original external callus persisting, despite the extensive transverse displacement that occurred.

Figure 24 shows classic endochondral bone formation on mineralized cartilage remnants as would be seen in normal metaphyseal bone formation. Surface osteoblasts immediately line woven bone once the latter has been deposited.

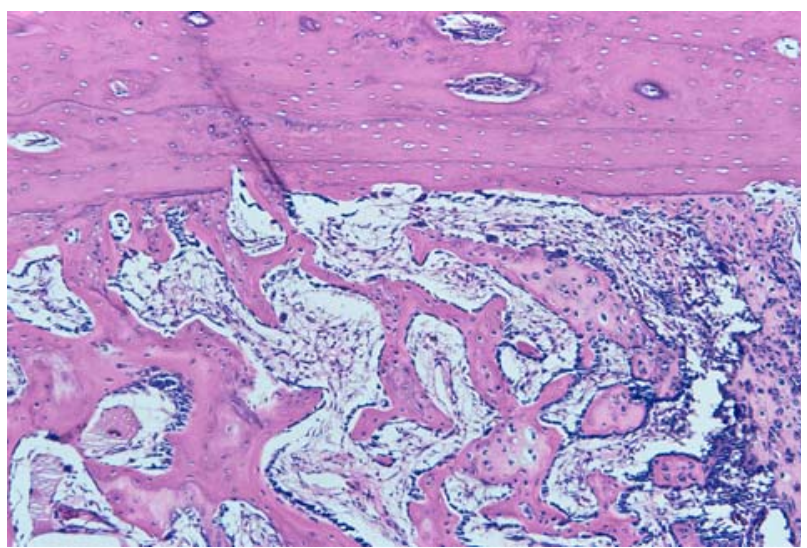

Figure 22 shows maturation of the initially synthesized periosteal woven new bone with surface osteoblasts and some lamellar segments now present.

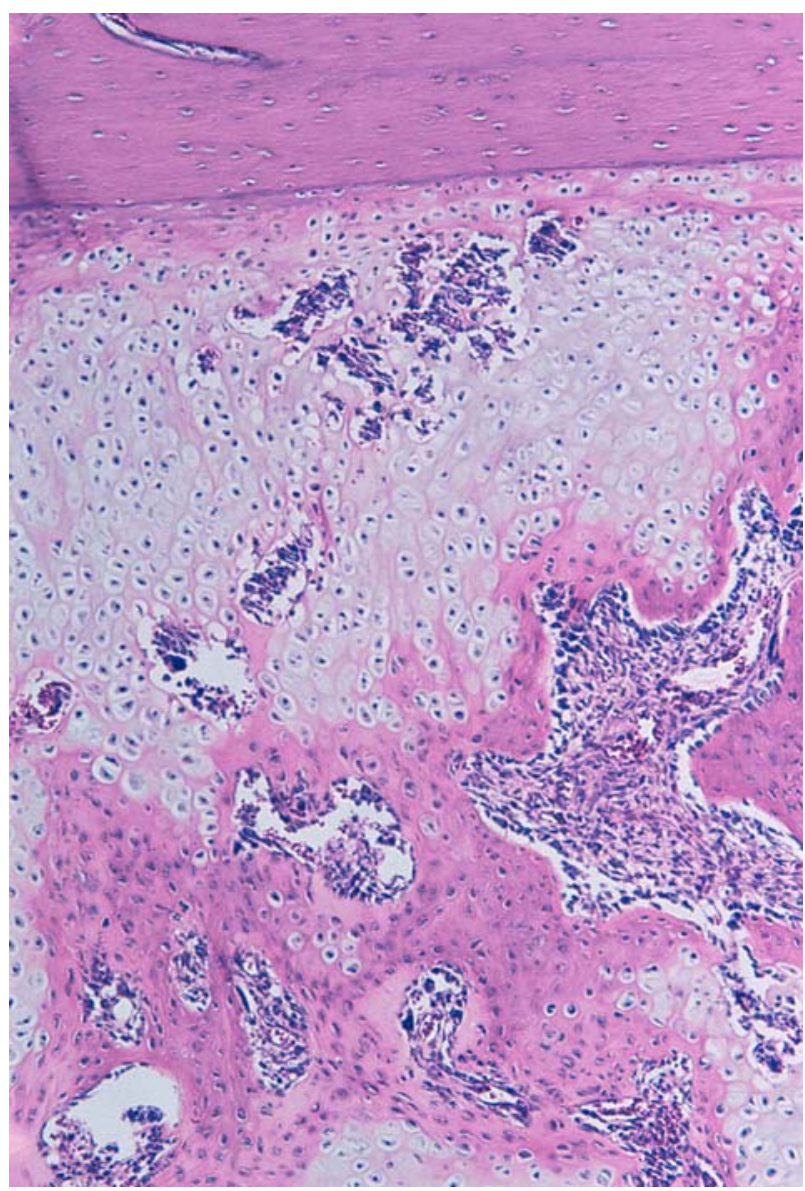

Figure 23 shows vascular invasion of the cartilage callus with new bone formation and surface osteoblasts.

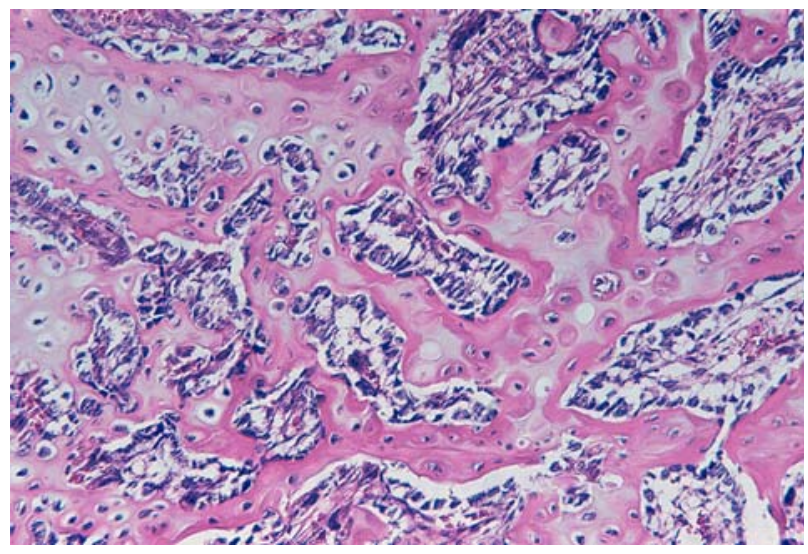




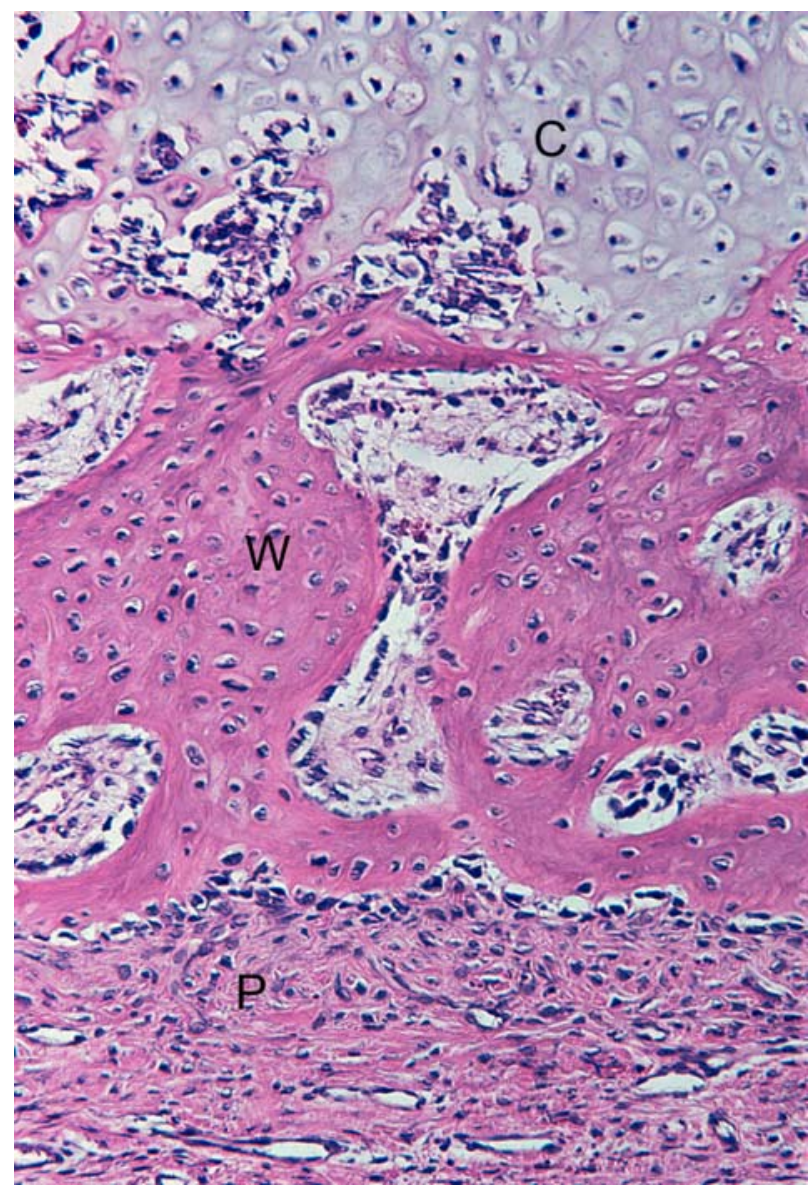

Figure 25 shows the outer fibrous layer of the periosteum (P) below, new woven bone formation (W) with some surface osteoblasts in place to continue bone formation with lamellar tissue, and cartilage at top (C) undergoing endochondral ossification.

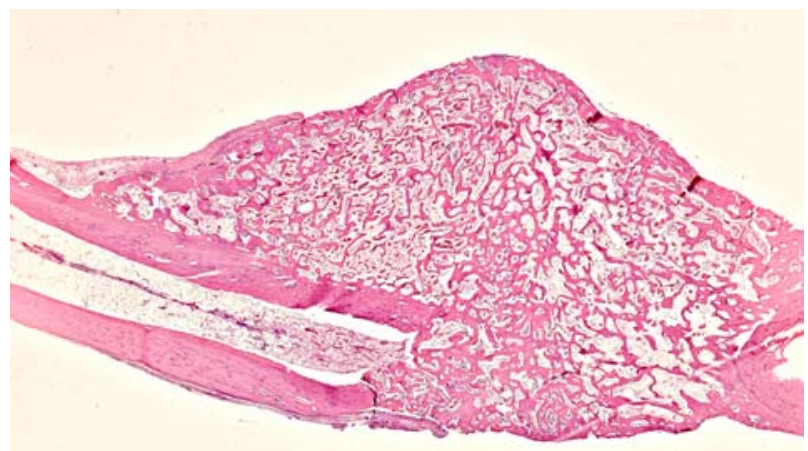

Figure 26. Fracture repair at 7 weeks is shown. The cortical fragments at left and far right are now fully bridged by repair bone. There is still a prominent external callus but all the cartilage tissue has been replaced by bone.

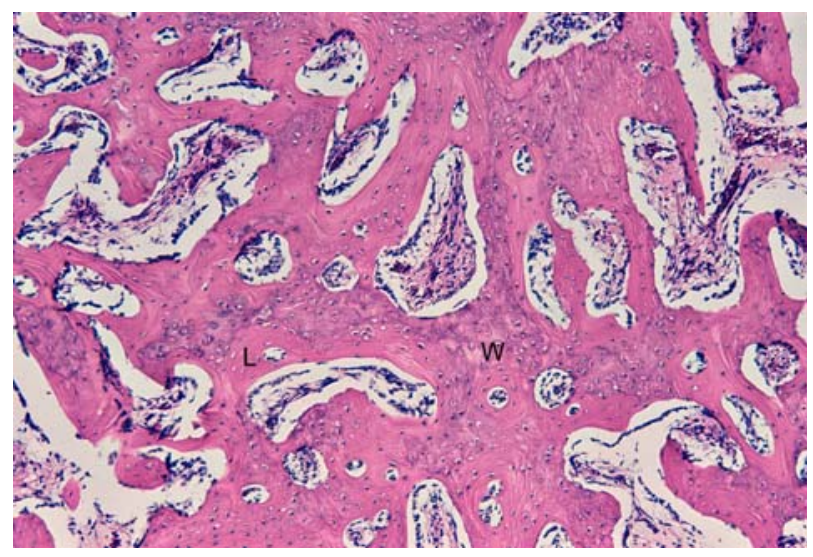

Figure 27. A higher power view from the central portion of the external callus of figure 26 shows woven bone (W), most of which has been covered with more recently synthesized lamellar bone (L). The lamellar bone is increasing and organizing to compact the tissue.

Figures 22 to 25 show higher power views from selected regions of figure 21 to demonstrate the tissue repair patterns as external callus bone is strengthened and remodelled towards normal cortical bone.

formed directly in the gap when that gap is $0.2 \mathrm{~mm}$ wide or less whereas larger gaps form woven bone initially and then lamellar.

Even with the classic compression plating studies of transverse osteotomies it was recognized that the cortex immediately under the plate was stabilized with no intergfragmentary gap allowing for primary transosteotomy Haversian bone or contact healing while the opposite cortex had a slight opening leading to the gap healing mechanism (Muller, 1978; Perren et al., 1969; Perren, 1979; Schenk and Willenegger, 1967) (Figs. 29, $30 \mathrm{a}$, and $30 \mathrm{~b}$ ). Repair by ingrowth of bone tissue initially perpendicular to the long axis of the bone with partial or complete transverse osteotomies has been noted by other observers (Olerud and Danckwardt-Lilliestrom, 1969; Wieder, 1907).

\section{Primary bone repair}

Primary bone repair, also referred to as contact healing, refers to bone repair within the cortex following anatomic reduction of a fracture and rigid internal fixation under compression, which eliminates any interfragmentary gap (Fig. 28). Repair occurs by synthesis of lamellar bone parallel to the long axis of the bone from osteoprogenitor cells in Haversian longitudinal vessels. A pathway through the dense cortical bone is made by what is referred to as an osteoclast-cutting cone where osteoclasts resorb bone and are immediately followed into the space created by vessel ingrowth and osteoblasts that synthesize lamellar matrix on the pre-existing cortical walls (Figs. 29, 30a, and $30 \mathrm{~b}$ ). The rigid plate stabilization eliminates the need for external callus formation and for entry of repair vessels and cells from the marrow since any fracture gap for them to enter has been closed. Since a dense and normally oriented scaffold for repair exists, in the form of the original cortex reduced and held by rigid compression fixation, surface osteoblasts suffice for repair without the need even for MOBL cells. This variant of bone repair has been characterized well in the dog radius (Perren et al., 1969; Perren, 1979; Schenk and Willenegger, 1964; Schenk and Willenegger, 1967; Schenk and Hunziker, 1994). 


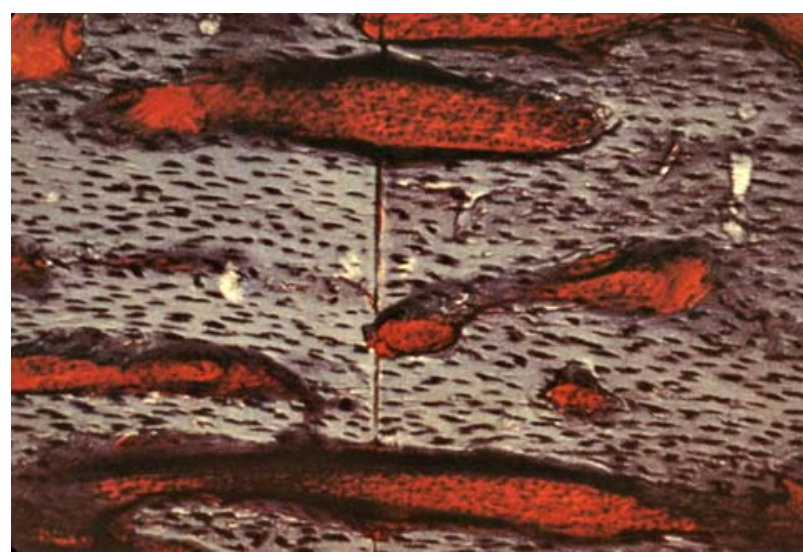

Figure 28. Photomicrograph illustrates primary bone repair following a non-displaced transverse osteotomy stabilized with rigid compression plating in the dog radius. Repair is occurring along the long axis of the bone within the cortex as osteoclast cutting cones from Haversian vessels cross the osteotomy line, core out a space, and then synthesize lamellar bone on the cortical walls along the longitudinal axis. (From Perren S, J Bone Joint Surg 2002; 84B: 1093-1110, reproduced with permission and copyright of the British Editorial Society of Bone and Joint Surgery.)

\section{Direct bone repair (oval defect)}

We assessed cortical bone repair in the adult chicken humerus after creating an oval unicortical $10 \mathrm{~mm} \times 3 \mathrm{~mm}$ defect with the long axis of the defect aligned along the shaft (Glimcher et al., 1980) [The unicortical defect models provide stability (since the large majority of the cortex remains intact circumferentially) but also interfragmentary space which can be varied in size and geometric shape.]. The entire sequence of bone repair was observed histologically from the early formation of a loose fibrous network in the haematoma clot to the eventual healing of the site with well-ordered lamellar bone eight weeks after operation. Stability is sufficiently great with this model, since most of the cylindrical cortex remains intact, that bone repair without mediation of a cartilage phase occurs but there is a range of tissue differentiation across the entire defect owing to its relatively large size and irregular geometry. Repair does not occur uniformly with the same tissue pattern across the entire defect. The initial synthesis of repair bone at one week is woven and localized adjacent to the persisting cortex. The four week specimen across the entire defect is extremely informative in terms of matrix deposition patterns since it captures the entire cascade of repair (Fig. 31). Bone at the periphery, which was originally woven is already being transformed into new osteonal lamellar bone adjacent to the persisting cortices. One can readily recognize the initially synthesized cores of woven bone around which lamellar bone has been deposited into early Haversian systems. Closer towards the centre of the defect woven bone predominates but some surface osteoblasts are now seen while in the centre of the defect undifferentiated mesenchymal cells persist which are just differentiating into mesenchymal osteoblasts and beginning to synthesize woven bone (Figs. 31 and 32). Repair was complete by 8 weeks with all bone tissue either remodelled or being remodelled to a lamellar conformation.

\section{Direct bone repair (circular defect)}

We have also assessed cortical bone repair in rabbit femoral and tibial cortical defects produced by $2.4 \mathrm{~mm}$ unicortical drill holes (Shapiro, 1988). This also allows for repair in a specific environment of rigid stability with an intersegmental gap of a specific size. This mechanism is often referred to as gap healing but we refer to it as direct transformational bone repair. We note new bone formation beginning in the marrow and advancing into the base of the defect by one week. Initially, new bone synthesis occurs peripherally, apposed to the pre-existing rim of lamellar cortical bone. The initial deposits on the cortex have a distinct woven matrix conformation. The repair process is associated with a rich vascular front which initially forms from the marrow and moves into the defect at right angles to the long axis of the bone. There is no bone formation initially from the periosteum or from the Haversian intracortical systems. Bone formation does not occur at a uniform rate across the entire defect. As one examines an

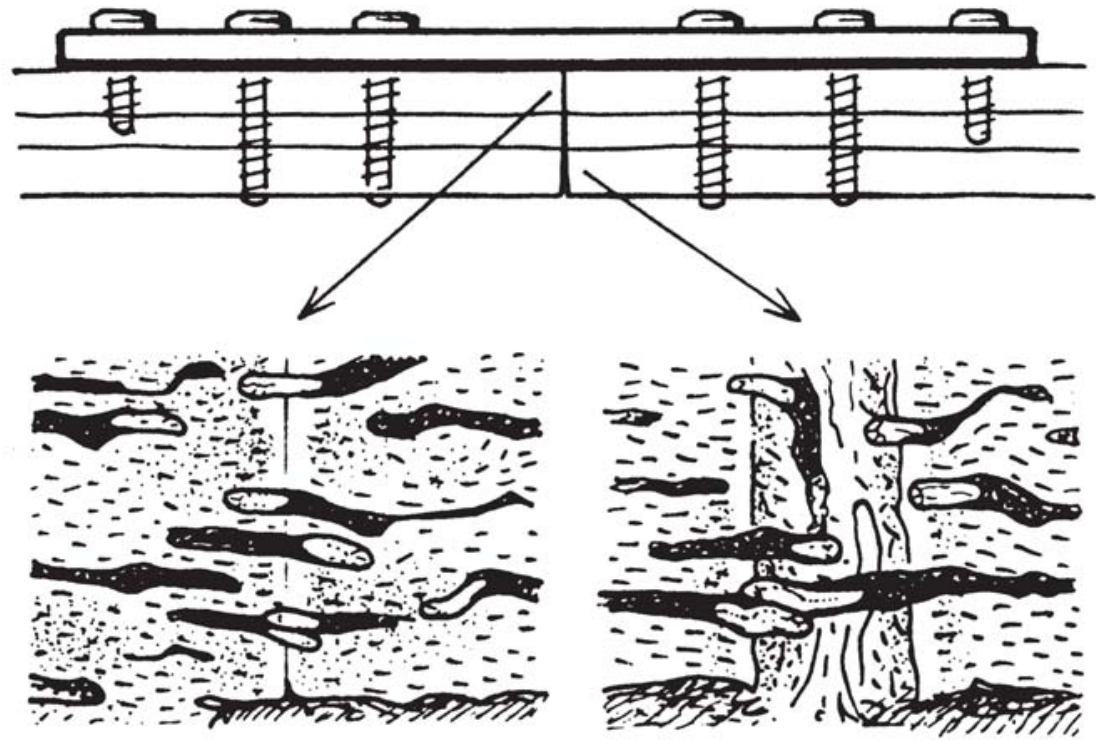

Figure 29. Illustration demonstrates the 2 types of repair that occur in the same bone following an osteotomy fixed with a rigid unicortical compression plate. In the cortex immediately under the plate there is no interfragmentary space and repair by the primary intracortical or contact mechanism occurs with lamellar bone synthesized initially along the longitudinal axis using the cutting cone mechanism. At the opposite cortex, slight opening occurs leading to repair with bone without a cartilage stage by the gap mechanism since the slight interfragmentary space allows for vascular invasion from the marrow cavity along with mesenchymal cells which synthesize lamellar bone at right angles to the longitudinal axis such that further remodelling will be needed. 

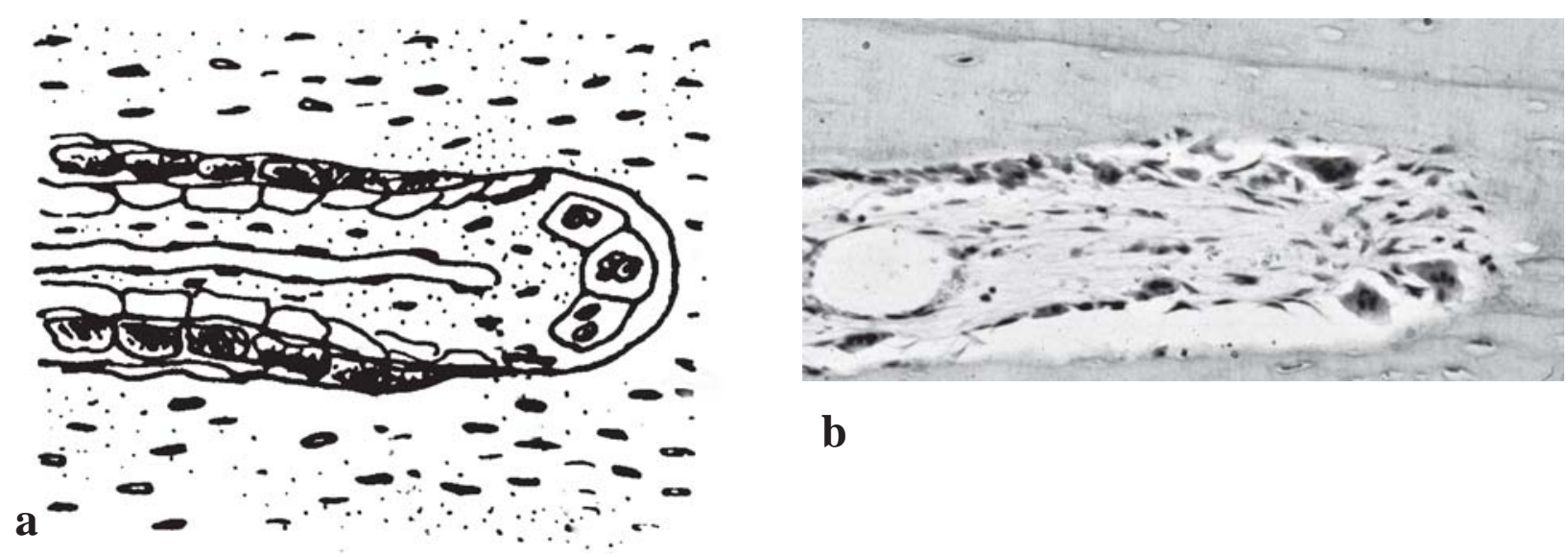

b

Figure 30. These figures illustrate osteoclast cutting cones. The diagram in (a) shows advancing activity passing from left to right led by the multinucleated osteoclasts which resorb bone followed by a central vessel and surface osteoblasts synthesizing lamellar bone. (b) illustrates a cutting cone passing through necrotic rabbit cortical bone to begin repair.

entire repair field from cortex to cortex, the central part of the defect is filled with mesenchymal cells and towards the periphery, repair is slightly more advanced with the mesenchymal cells having differentiated into mesenchymal osteoblasts which surround themselves with a woven bone matrix (Fig. 33). By 2 weeks, the initially synthesized woven matrix at the periphery of the defect begins to be surrounded itself by a better oriented, essentially lamellar matrix, rimmed in orderly fashion by surface osteoblasts. By 3 weeks, repair bone has filled the defect. The accumulations of woven bone are now rimmed completely by plump surface osteoblasts and resorption of woven bone segments by multi-nucleated osteoclasts is underway. A distinction is seen between mesenchymal osteoblasts, which surround themselves with an osteoid matrix of woven conformation, and surface osteoblasts, which lay down osteoid in lamellar conformation on the previously synthesized woven matrix. The surface osteoblasts lay down bone in the lamellar conformation quite early once a scaffold of woven bone matrix has been deposited.

The proportion of lamellar bone increases quickly such that only a few cores of woven bone persist at four weeks. The lamellar repair bone becomes organized into the Haversian system-osteonal conformation. As the initial vascular ingrowth is from the marrow cavity, and as this pattern persists, the Haversian systems deposited are parallel to the vessels and at right angles to the Haversian systems of the undamaged cortex. The earliest signs of linkage of the intracortical Haversian vessels and vessels at the site of the defect are seen at two weeks, but they are more prominent by three weeks as multiple osteoclast cutting cones, followed by osteoblasts, form. By six to eight weeks, Haversian systems from the pre-existing cortex are beginning to traverse the peripheral parts of the repair bone, but the alignment of the matrix and vessels of the repair bone throughout the site of the defect is still predominantly at right angles to the long axis of the cortex as long as twelve weeks after operation (Fig. 34). Polarizing light microscopy shows lamellar repair but markedly different fibril plane orientation even several weeks after injury.

The lamellar repair bone osteocytes are long, oval, and elliptical; their long axes are aligned parallel to the

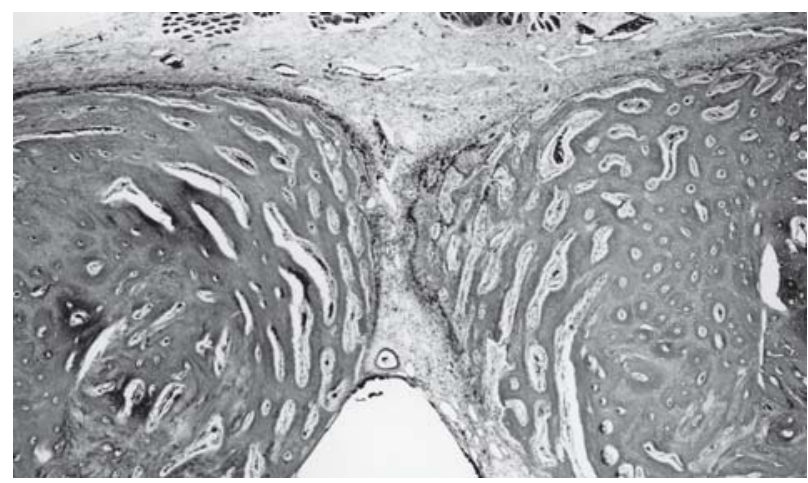

Figure 31. Photomicrograph shows a section completely traversing the repair site from cortex to cortex in a chicken humerus oval cortical defect model at 4 weeks post-injury. The intact persisting cortices are at far right and left. Centrally there are a few undifferentiated mesenchymal cells. In adjacent regions away from the centre the mesenchymal cells have differentiated to mesenchymal osteoblasts synthesizing woven bone. Closer to the cortex, where the initial repair began with woven bone synthesized on the cortical scaffold, further new bone formation by surface osteoblasts has led to new osteonal bone formation on the woven bone tissue.

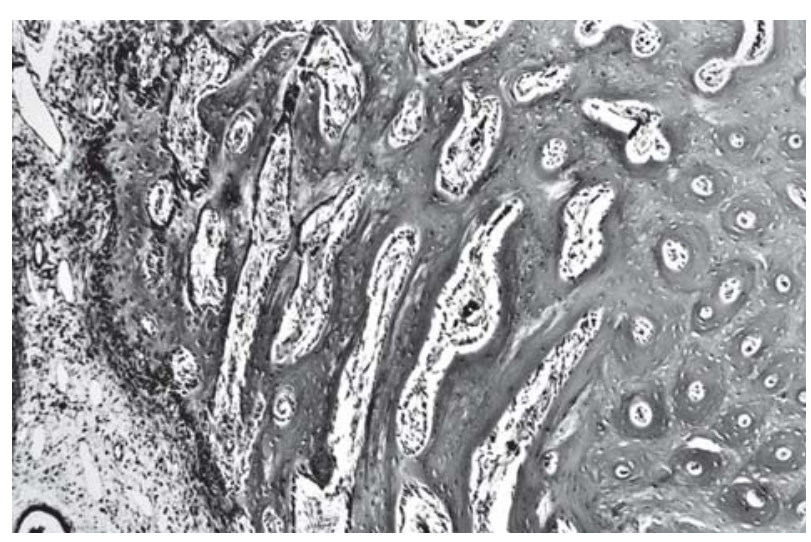

Figure 32. A higher power view of one side of the defect shows the undifferentiated cells at far left and the repair cascade passing to the right. At far right there is lamellar osteonal bone formation on woven tissue. These 2 photomicrographs illustrate the cascade of repair showing that the entire gap does not undergo repair with the same tissue at the same time but that repair begins peripherally, using the persisting cortex as a scaffold, and then passes towards the centre of the defect, the region that heals latest. 


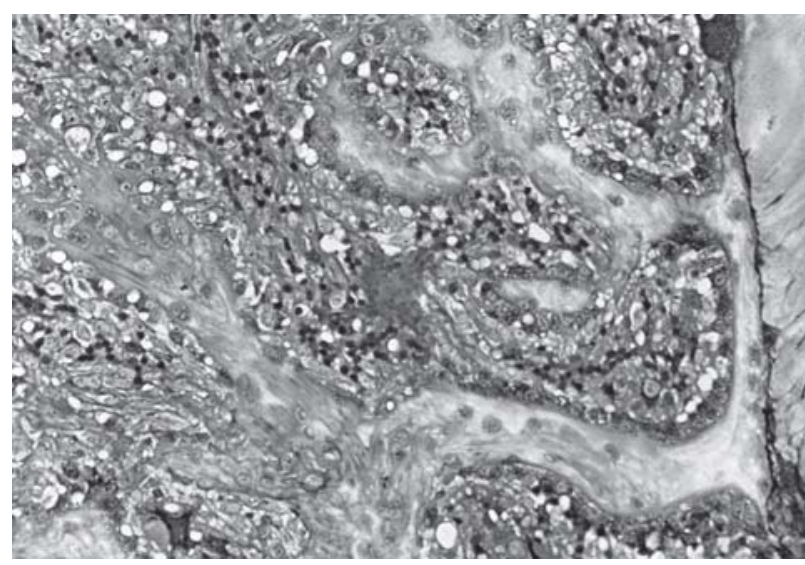

Figure 33. Photomicrograph at 2 weeks shows woven bone forming by mesenchymal osteoblasts (at left) near the centre of the defect. Original synthesis of a thin rim of lamellar bone on the persisting cortex has occurred (at right) and this is immediately rimmed with a layer of surface osteoblasts.

Figure 34. Photomicrograph at 8 weeks shows the gap to be filled with bone in lamellar conformation although the long axis of repair (at left), which has followed the axis of vascular invasion, is at right angles to the original cortex. Osteoclast cutting cone remodelling is beginning at lower right from the original cortex into the repair tissue to remodel and realign the lamellar bone along the longitudinal axis..

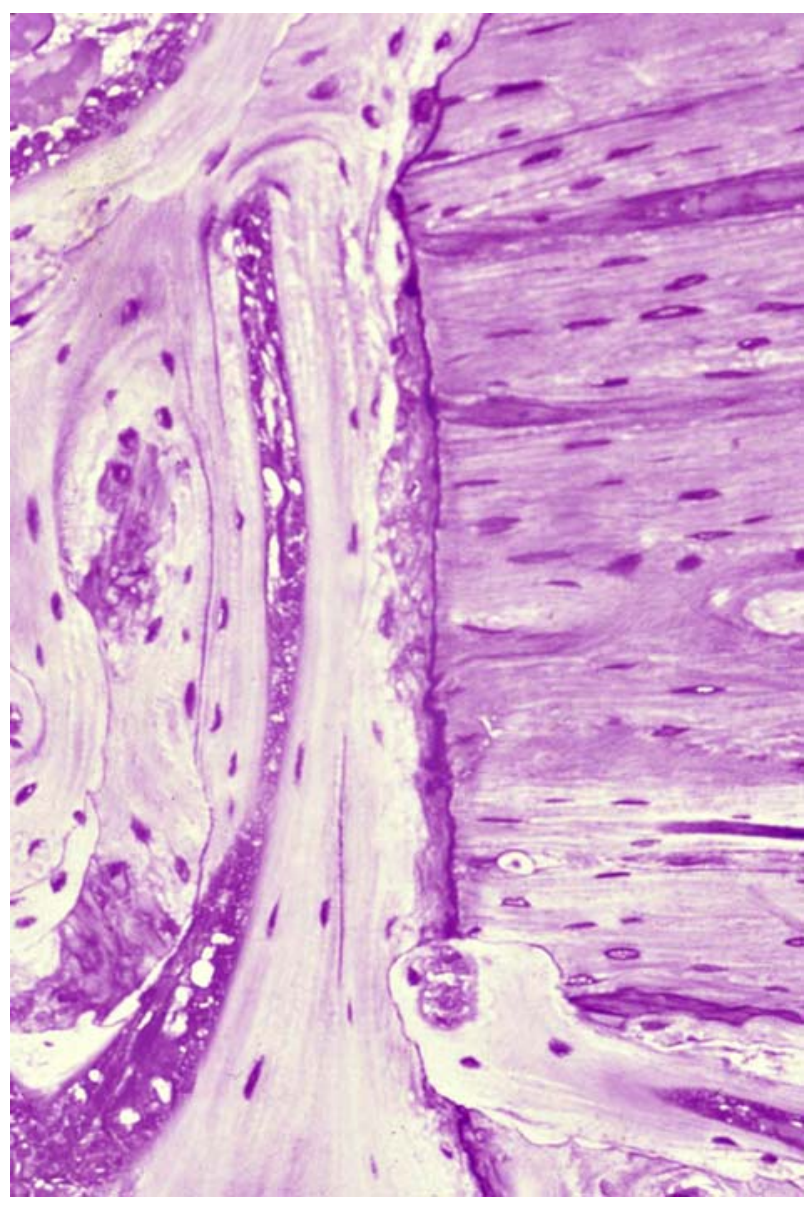

Figures 33 and 34 illustrate direct transformational bone repair in a $2.4 \mathrm{~mm}$ cortical defect model in the rabbit tibia.

lamellation and thus perpendicular to the long axes of the lacunae in the adjacent cortical lamellar bone. The canaliculi are well developed and show the characteristic and more regular orientation of normal cortical canaliculi. The canaliculi in repair woven bone osteocytes pass out from the round cell bodies in poorly aligned fashion, whereas those from the elongated lamellar repair osteocytes are well aligned.

This pattern for repair in circular defects has been described in the works of other investigators and is a welldocumented phenomenon (Draenert and Draenert, 1980; Johner, 1972; Schenk and Willenegger, 1977). Close examination of several studies that used a cortical drillhole model indicates that woven bone is sometimes formed initially at one week in defects that are as small as $0.2 \mathrm{~mm}$ as well as in $0.5-\mathrm{mm}$ defects, the $2.4 \mathrm{~mm}$ defect that we reported, and the even larger oval defect in the chicken humerus. If defects as small as $0.2 \mathrm{~mm}$ demonstrate formation of woven bone initially, then much healing with rigid fixation in clinical situations occurs by the mechanism described as gap healing or direct transformational bone repair. Even when the mesenchymal cells pass directly to lamellar conformation, for example as surface osteoblasts deposit bone on the persisting cortex when the gap measures only 0.01 to $0.2 \mathrm{~mm}$, the source and orientation of repair cells, vessels, and matrices indicate a different mechanism than truly primary trans-Haversian repair, in that osteonal remodelling must still occur. The presence of lamellar bone at right angles or perpendicular to the long axis of the bone implies a point of structural weakness not fully strengthened until remodelling the osteons of repair bone along the longitudinal axis (Olerud and Danckwardt-Lilliestrom, 1968; Perren et al., 1969; Schenk and Willenegger, 1967; Shapiro, 1988). Studies of bone defect models in stable environments help to identify the specific effects on repair of the size and stability of the gap (Claes et al., 1997; Perren, 1979) and the effects of mechanical stability on repair bone vascularity (Claes et al., 2002).

\section{Distraction osteogenesis}

The final mechanism of bone repair is distraction osteogenesis, where bone formation occurs in a stable environment due to external fixation but one subjected to intermittent or continuous incremental lengthening. This mechanism was identified in relation to long bone lengthening to allow bone repair to occur without need for additional internal stabilization or bone grafting. We performed distraction osteogenesis of the tibia in a rabbit model using an external fixator (Figs. 35 to 40). Shortly after osteotomy blood clot is present within the marrow cavity and surrounding the osteotomy site. Histologic sections reveal a collection of the red blood cells within a fibrillar mass. The majority of initial repair emanates from the periosteal site but the marrow site is soon involved. There is a sharp demarcation of repair within the marrow 


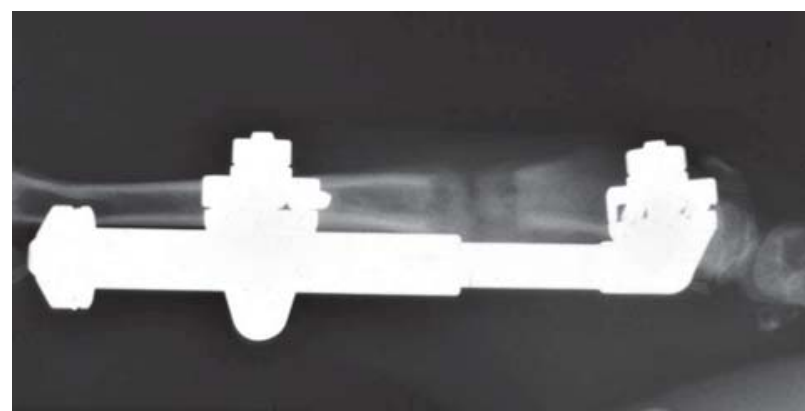

Figure 35. Lateral radiograph of tibia at 3 weeks shows distraction gap with a central lucent region (the fibrous interzone) and more radiodense bone formation passing from each cortex towards the centre of the distraction gap.

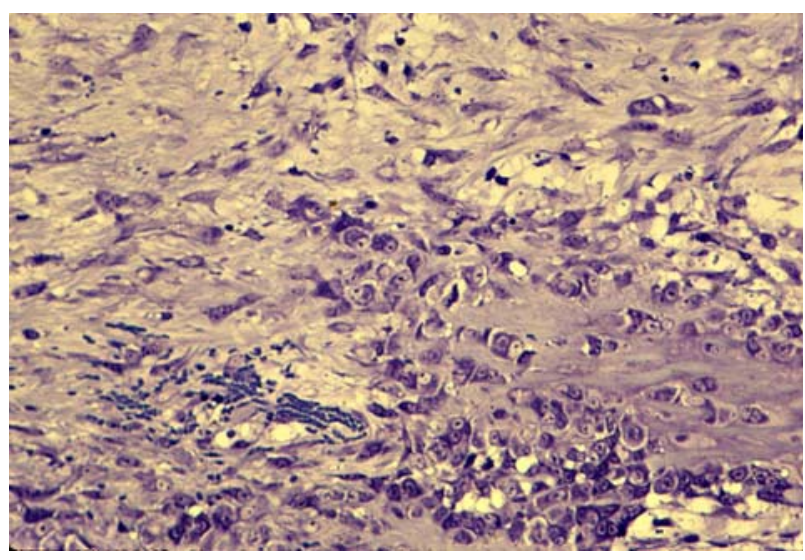

Figure 36. Photomicrograph of repair tissue from the central gap region at one week shows undifferentiated mesenchymal cells at left with early differentiation leading progressively (left to right) to mesenchymal osteoblasts synthesizing woven bone and, at far right, a few surface osteoblasts on the woven scaffold.

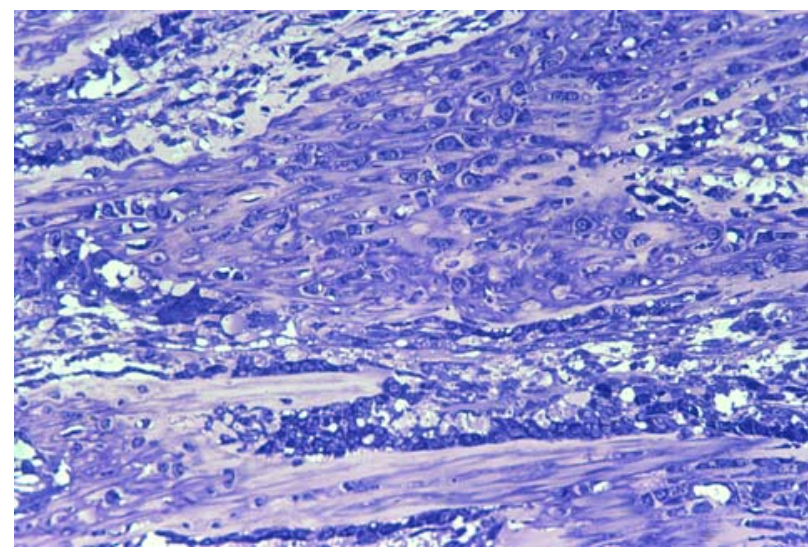

Figure 37. Closer towards the persisting cortex woven bone is seen with surface osteoblasts synthesizing lamellar bone at bottom of photomicrograph. The longitudinal orientation of repair tissue in distraction osteogenesis is shown proceeding to membranous bone formation.

Figures 35 to 40 . These figures illustrate repair by distraction osteogenesis in a rabbit tibia undergoing lengthening with a mini-lengthener.

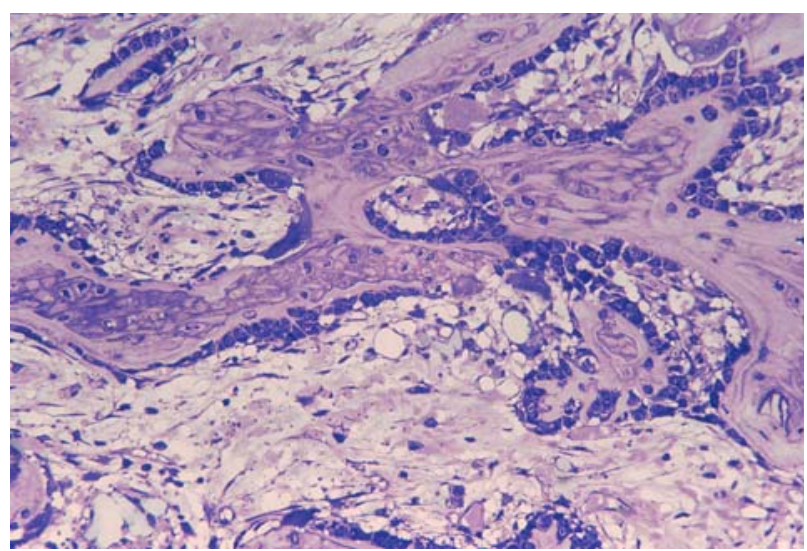

Figure 38. Photomicrograph illustrates repair tissue further towards the original cortex where initially synthesized woven bone has been surrounded by lamellar bone and surface osteoblasts.

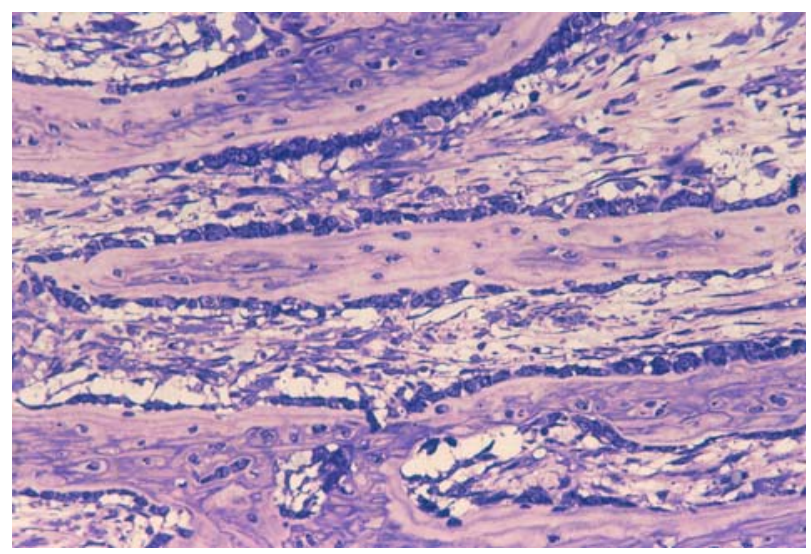

Figure 39. Repair lamellar bone with surface osteoblasts begins to predominate nearer the original cortex with cell alignment along the longitudinal distraction and long bone axis.

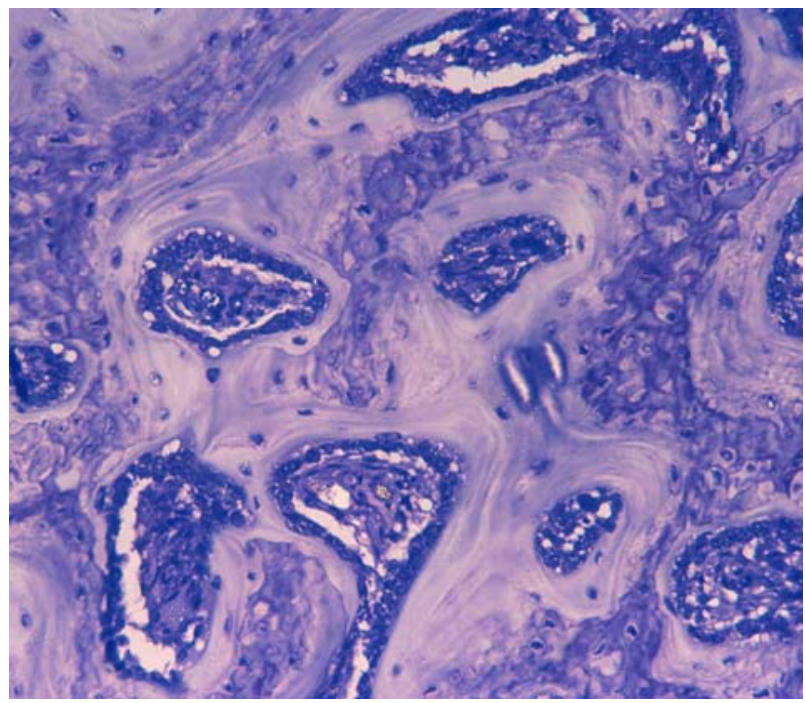

Figure 40. By 6 weeks the gap is filled with new bone. This transverse section (to long axis of the bone) shows some initial woven bone (deep purple) surrounded by lamellar bone (lighter purple) and surface osteoblasts filling in spaces with conversion to lamellar osteonal orientation. 
cavity between the gap region where cellular responses are quite active and the persisting marrow, which remains quiet virtually up to the line of osteotomy. At 3-4 days fibrinous clot is seen in the distraction gap with blood vessel and mesenchymal cell invasion from the persisting marrow cavity and rapidly reconstituting periosteum. At 7 days woven bone synthesis is noted with initial deposition on the cut cortical bone ends. Marrow vessel continuity is restored within several days after sectioning the intramedullary vasculature. At 14-21 days a central lucent zone in the widening distraction gap is present radiographically (Fig. 35) and a spectrum of regenerate bone is seen histologically (Figs. 36 to 40). Repair is not uniform along the length of the distraction gap. Adjacent to cortical ends lamellar bone on initially deposited woven bone cores predominates and as repair is assessed toward the central zone correspondingly less mature repair tissue is seen ranging from woven bone to mesenchymal osteoblasts to undifferentiated mesenchymal cells at the central radiolucent regions. The sequence is repeated from the opposite cortical bone ends to the centre of the distraction gap. There is a definite tendency for the newly synthesized woven bone to be aligned in longitudinal fashion parallel to and along the longitudinal axis of distraction (Figs. 37-39). Intense osteoclast mediated resorption of the initially synthesized woven bone occurs along with repair. On occasion foci of cartilage are seen at the periphery of the distraction gap adjacent to the elevated periosteum. Cartilage does not form however in the gap tissues along the long axis of distraction. In specimens greater than 40 days post surgery reformation of a lamellar cortex and fatty marrow are seen. A historical review of callus distraction in limb lengthening has been written by Wiedemann (1996). This mechanism of repair has been defined in whole or in part at the histologic level by several investigators (Aronson et al., 1989; Delloye et al., 1990; Ilizarov, 1989; Kojimoto et al., 1988; Krompecher, 1934, 1937, 1956; Peltonen et al., 1992; Yasui et al., 1997).

In most instances of distraction osteogenesis there is direct intramembranous bone formation. The initial healing response of the mesenchymal cell leads to the formation of osteoid, which is normally present in random orientation characteristic of woven bone. The longitudinal distraction, however, tends to align the collagen fibrils of the woven bone deposition along the long axis. The central region of the distraction gap is filled with the least differentiated mesenchymal cells that appear as fibroblasts and vascular progenitor cells. Shortly after woven bone has been synthesized the osteoblasts align themselves preferentially on the surface and synthesize bone in a lamellar pattern. By 3 weeks when distraction has been discontinued the entire distraction gap has been filled with new bone. This is concentrated exclusively, however, in the cortical and sub-periosteal regions with some bone seen within the marrow cavity but essentially no new bone in the marrow proximal or distal to the osteotomy sites. With time the woven bone is resorbed and bone with a lamellar conformation deposited. The distraction model also shows the MOBL/SOBL interplay.

\section{Possible other mechanisms of bone repair via fibro- osseous and chondro-osseous tissue accumulations}

For several decades, infrequent but recurring papers and studies on bone development and repair have raised the question of other mechanisms, usually encompassing bone synthesis via fibro-osseous or chondro-osseous tissue accumulations. There is no doubt that these appearances can be seen on histological sections in some animal models and in human tissue descriptions. As a rule, such findings are associated with bone that is undergoing imperfect healing such as with pseudarthrosis or delayed union. The context where such repair can be seen is with relatively excess motion and relatively poor blood supply where both fibrous and cartilaginous elements are favoured but stability is sufficient that bone repair is attempting to gain a foothold. This might help explain the finding of "chondroid" bone formation by some in distraction osteogenesis models in murine species (Yasui et al., 1997). Observations on chondrocytes directly synthesizing bone have been made from tissue culture and embryo studies of hypertrophic chondrocytes seemingly differentiating into osteoblast-like cells rather than all undergoing apoptosis (Galotto, et al., 1994; Roach, 1992). It needs to be recognized that many molecules are synthesized by both chondrocytes and osteoblasts and cannot be used to define one tissue type from another. As a general rule, these tissue accumulations do not underlie a dependable route for solid bone repair and unless the mechanical environment is stabilized they may be precursors of a state of pseudarthrosis.

\section{The lacunar-canalicular system}

The canalicular framework in woven and lamellar bone shows the changes in orientation and extensiveness during both development (Burger and Klein-Nuland, 1999) and repair (Kusuzaki et al., 2000; Shapiro, 1988). The data on normal cortical osteocytes show excellent uniformity in terms of cellular shape, position, length and width, and frequency of canalicular offshoots. Lamellar bone osteocytes are elongated and elliptical in shape, and lie parallel to the long axis of the lamellae (Figure 9). The data in our study (Shapiro, 1988) show the ratio of length to width in control osteocytes to be 3.5 to one. The number of canaliculi emanating from a lacuna has been expressed as a perimeter-to-canalicular ratio, with the value obtained representing the average distance, in $\mu \mathrm{m}$, between each canaliculus. This value is uniform in the normal mature cortical osteocyte, being $1.9 \mu \mathrm{m}$ (standard deviation, 0.2 ) over the cell surface. The repair data show the woven bone osteocytes that have just differentiated from mesenchymal cells to have a length to width ratio of 1.8 to one, consistent with their round-to-oval appearance. The repair lamellar osteocytes progressively take on the shape of mature osteocytes, and at four weeks the average ratio of length to width has reached $2.4: 1$. The data on repair also demonstrate the development of uniformity in the number of canaliculi that pass out from each lacuna. The value in repair lamellar bone osteocytes is comparable with that in mature cortical lamellar bone in the two to four-week time frame, a value of $2.4 \mu \mathrm{m}$ for the perimeter-to-canalicular ratio having been documented. Woven bone osteocytes 
show fewer canalicular offshoots by light microscopy, having a perimeter-to-canalicular ratio of 5.6 at two and three weeks, but this may be due partially to an inability to demonstrate them, since they take a tortuous route through the woven matrix. Development of the cell processes occurs during the first several days of repair, since transmission electron micrographs at one week show mesenchymal cells in the central parts of the defect to be without processes, whereas processes are clearly evident in woven and lamellar osteoblasts and osteocytes some days later. Scanning electron microscopic studies show extensive cell processes of osteoblasts during development.

The lacunar-canalicular system plays a dual role in the repair and maintenance of bone. By linking osteoblasts, osteocytes, and blood vessels, it allows the extracellular fluid to relate to the matrix and the vascular system, providing nutrition to the bone cells and allowing deposition and removal of mineral. Extracellular fluids pass through the intracanalicular system but whether the preferred pathway is via an extracellular, extra-process position, being outside the actual cells and cell-processes, is unclear. The changing topography of the lacunarcanalicular system and the presence ultrastructurally of intermediate filaments (Shapiro et al., 1995) and intercellular gap junctions (Shapiro, 1997) imply an active cell-cell communication role for the system, mediated in an intracanalicular intracellular fashion. Transmission electron micrographs demonstrate intracellular intermediate filaments, approximately $11 \mathrm{~nm}$ in diameter, within the mesenchymal cells and osteoblasts and within the osteoblast and osteocyte cell processes as well as $7 \mathrm{~nm}$ thick actin filaments in longitudinal array (Fig. 10). The large number of canaliculi implies a major functional role for the cell processes and their filaments. Transmission electron microscopic studies document intercellular gap junctions between surface osteoblasts, between osteoblasts and osteocyte processes in the bone, between adjacent osteocytes (via cell processes), between endosteal cortical bone-lining cells, and between osteocytes and intracortical blood vessels (Fig. 11). The length of the gap junctions is frequently quite extensive especially along the long axis of cell processes. The surface area of the gap junctions is frequently increased by curvilinear, stacked linear or annular shapes (Shapiro, 1997).

\section{Metaphyseal and trabecular bone repair}

Fractures in metaphyses or spongy bone heal in a much more rapid fashion and with fewer problems than cortical fractures. There is direct bone formation without the need for extraperiosteal callus or cartilage formation since the fractures: i) tend to be impacted and stable; ii) occur in the highly vascularized metaphyseal marrow; and iii) occur amidst bone trabeculae within the marrow which immediately present a very large surface area upon which new repair bone can be deposited. Fractures through the metaphyses show only a few mm of necrotic tissue while those in dense cortical bone have more extensive evidence of empty osteocyte lacunae. There has been high clinical awareness of the tendency to rapid repair with metaphyseal fractures but several studies provided histologic evidence
(Charnley and Baker, 1952; Uhthoff and Rahn, 1981; Urist and Johnson, 1943). Charnley performed knee arthrodeses with a compression device after removing the cartilage surfaces and apposing flattened femoral and tibial metaphyseal tissue. Histologic biopsies taken by a core along the line of union 4 weeks post surgery showed bone repair with woven bone initially apposed to trabecular surfaces followed rapidly, in adjacent regions, by lamellar bone deposition. The repair was so efficient that there was only a slightly increased amount of bone tissue present. Repair trabeculae tended to link pre-existing trabeculae from femoral and tibial sides. There was absence of cartilage tissue, interpreted as evidence of a lack of interfragmentary mobility. The efficiency of repair was due to the fact that osteoblastic action was confined to bone surfaces which are extensive in cancellous bone compared to cortical bone. Charnley and Baker (1952) observed that the woven bone trabeculae soon increase in thickness by surface deposition of new bone matrix, the fibres of which, instead of being arranged irregularly as in the woven bone, were arranged in sheets parallel to the surface forming imperfectly lamellar bone which, with time would become more mature. Uhthoff and Rahn (1981) showed the same findings in experimental animal models (rats, rabbits, dogs) in whom they made stable metaphyseal fractures. As long as the fractures didn't displace, trabeculae throughout the region were lined with osteoblasts, cartilage did not form internally and no periosteal callus was observed. The closing of the gap occurred through the deposition of lamellar or woven bone on existing trabeculae or through interposition of woven bone.

\section{Bone repair mechanisms in a clinical setting}

Knowledge of the several mechanisms of bone repair is important for optimal clinical management of fractures, osteotomies and bone fusion procedures and for the development of future operative and non-operative interventions to enhance bone repair. Bone has a remarkable ability to repair itself to full structural and functional effectiveness. The ideal end result of repair should be a complete reconstitution of lamellar bone oriented along the longitudinal axis of the bone, merged across the fracture site with a seamless incorporation into the adjacent bone, and remodelled to the point of no indication as to where the fracture or osteotomy was. The biomechanical environment for repair, chosen to a great extent by the surgeon, leads to different mechanisms of repair but the end result of full repair is the same. If stabilization is by cast, splint or traction then the endochondral repair mechanism mediated through cartilage synthesis is activated. Rigid internal fixation with anatomic reduction, compression, and an absence of the interfragmentary gap can lead to primary bone union within the cortex along the Haversian canals via osteoclast cutting cones. Much rigid internal fixation however, especially with osteotomies where segments of bone are removed and dissimilar cortices reapposed, leads to repair without external callus but by the mechanism of gap or direct transformational bone repair. Over the past several years there has been awareness that compression plates can cause 
localized devascularization and osteopenia leaving the underlying cortex weakened and subject to delayed fracture after plate removal. This has led to further innovations in plate stabilization, such as the limited contact dynamic compression plate (LC-DCP), and locking plates with unicortical (or bicortical) fixation where the tightness is between the plate and the screw rather than the plate and the underlying bone cortex surface. Perren (2002) has detailed the concept of biological internal fixation designed to minimize damage to the blood supply both by limiting periosteal elevation and lessening the direct bone contact and rigidity of plate stabilization. This still allows for effective repair but switches the mechanism to direct transformational bone repair (gap healing) and in some instances to elements of endochondral bone repair for the biologic stabilization. Regardless of the techniques used, it is incumbent on the surgeon to understand and control the repair mechanisms being triggered.

\section{Acknowledgements}

This work was supported in part by the Peabody Foundation, Boston, MA. The author thanks Evelyn Flynn for histology preparations and James Koepfler of the Orthopedic Resource Center, Children's Hospital Boston.

\section{References}

Aronson J, Harrison BH, Stewart CL, Harp JH Jr (1989) The histology of distraction osteogenesis using different external fixators. Clin Orthop Rel Res 241: 106-116.

Barnes GL, Kostenuik PJ, Gerstenfeld LC, Einhorn TA (1999) Growth factor regulation of fracture repair. J Bone Miner Res 14: 1805-1815.

Bassett CAL, Becker RO (1962) Generation of electric potentials by bone in response to mechanical stress. Science 137: 1063-1064.

Basset CAL, Pawluk RJ, Becker RO (1964) Effects of electric currents on bone in vivo. Nature 204: 652-654.

Bassett CAL, Mitchell SN, Gaston SR (1982) Pulsing electromagnetic field treatment in ununited fractures and failed arthrodeses. J Am Med Assoc 247: 623-628.

Borgens RB (1984) Endogenous ionic currents traverse intact and damaged bone. Science 225: 478-482.

Bouligand Y, Denefle J-P, Lechaire J-P, Maillard M (1985) Twisted architectures in cell-free assembled collagen gels: study of collagen substrates used for cultures. Biol Cell 54: 143-162.

Brighton CT (1981) The treatment of non-unions with electricity. J Bone Joint Surg [Am] 63: 847-851.

Burger EH, Klein-Nuland J (1999) Mechanotransduction in bone-role of lacuno-canalicular network. FASEB J 13(Suppl): S101-S112.

Carter DR, Beaupre GS, Giori NJ, Helms JA (1998) Mechanobiology of skeletal regeneration. Clin Orthop Rel Res 355S: S41-S55.

Chao E, Inoue N (2003) Biophysical stimulation of bone fracture repair, regeneration and remodelling. Eur Cell Mater 6: 72-85.
Charnley J, Baker SL (1952) Compression arthrodesis of the knee. A clinical and histological study. J Bone Joint Surg [Br] 34: 187-199.

Cisneros DA, Hung C, Franz CM, Muller DJ (2006) Observing growth steps of collagen self-assembly by timelapse high-resolution atomic force microscopy. J Struc Biol 154: 232-245.

Claes LE, Heigele CA (1999) Magnitudes of local stress and strain along bony surfaces predict the course and type of fracture healing. J Biomech 32: 255-266.

Claes L, Augat P, Suger G, Wilke, H-J (1997) Influence of size and stability of the osteotomy gap on the success of fracture healing. J Orthop Res 15: 577-584.

Claes L, Eckert-Hubner K, Augat P (2002) The effect of mechanical stability on local vascularization and tissue differentiation in callus healing. J Orthop Res 20: 10991105 .

Cornil V, Coudray P (1904) Du cal. Au point de vue experimental et histologique [The callus. From the experimental and histological point of view]. J Anat Physiol 40: 113-179.

Dale GG, Harris WR (1958) Prognosis of epiphysial separations. An experimental study. J Bone Joint Surg [Br] 40: $116-122$.

Delloye C, Delefortrie G, Coutelier L, Vincent A (1990) Bone regenerate formation in cortical bone during distraction lengthening. Clin Orthop Rel Res 250: 34-42.

Draenert Y, Draenert K (1980) Gap healing of compact bone. Scan Elec Microsc 1980/IV: 103-111.

Duncan RL, Turner CH (1995) Mechanotransduction and the functional response of bone to mechanical strains. Calcif Tissue Int 57: 344-358.

Dupuytren G (1847) On the formation of callus; and on the means of remedying its faulty or misshapen deposit. In: On the Injuries and Diseases of Bones (Le Gros Clark F, ed and transl) Sydenham Society, London. pp. 40-72.

Einhorn TA (1998) The cell and molecular biology of fracture healing. Clin Orthop Rel Res 355S: S7-S21.

Ferguson C, Alpern E, Miclau T, Helms JA(1999) Does adult fracture repair recapitulate embryonic skeletal formation? Mech Dev 87: 57-66.

Foote JS (1916) A contribution to the comparative histology of the femur. Smithsonian Contributions to Knowledge 35: 1-230.

Forriol F, Shapiro F (2005) Bone development. Interaction of molecular components and biophysical forces. Clin Orthop Rel Res 432: 14-33.

Friedenberg ZB, Brighton CT (1966) Bioelectric potentials in bone. J Bone Joint Surg [Am] 48: 915-923.

Galotto M, Campanile G, Robino G, Descalzi Cancedda F, Bianco P, Cancedda R (1994) Hypertrophic chondrocytes undergo further differentiation to osteoblastlike cells and participate in the initial bone formation in developing chick embryo. J Bone Miner Res 9: 1239-1249.

Gebhardt W (1905) Uber funktionell wichtige Anordnungsweisen der feineren und groberen Bauelemente des Wirbeltierknochens. II. Spezieller Teil. I. Der Bau der Haversschen Lamellensysteme und seine funktionelle Bedeutung [On functionally important structures of the finer and coarser building blocks of the vertebrate bone. II. Special part. The structure of the 
Haversian lamellar system and its functional significance]. Roux Arch f Entwickl d Organ 20: 187-322.

Gerstenfeld LC, Cullinane DM, Barnes GL, Graves DT, Einhorn TA (2003) Fracture healing as a post-natal developmental process: molecular, spatial, and temporal aspects of its regulation. J Cell Biochem 88: 873-884.

Glimcher MJ, Shapiro F, Ellis RD, Eyre DR (1980) Changes in tissue morphology and collagen composition during the repair of cortical bone in the adult chicken. J Bone Joint Surg [Am] 62: 964-973.

Giraud-Guille MM (1988) Twisted plywood architecture of collagen fibrils in human compact bone osteons. Calcif Tissue Int 42: 167-180.

Haines RW (1933) Cartilage canals. J Anat 68: 45-64.

Ham AW, Harris WR (1971) Repair and transplantation of bone. In: The Biochemistry and Physiology of Bone, $2^{\text {nd }}$ ed (Bourne GH, ed) Academic Press, New York. pp. 337-399.

Ham AW (1979) The healing of a simple fracture of a long bone. In: Histology, $8^{\text {th }}$ ed (Ham AW, Crmack DH, eds) Lippincott, Philadelphia. pp. 450-455.

Henderson JH, Carter DR (2002) Mechanical induction in limb morphogenesis. The role of growth-generated strains and pressures. Bone 31: 645-653.

Ilizarov GA (1989) The tension-stress effect on the genesis and growth of tissues. Part 1. The influence of stability of fixation and soft-tissue preservation. Clin Orthop Rel Res 238: 249-281.

Jaffe HL (1929) The structure of bone. Arch Surg 19: 24-52.

Johner R (1972) Zur Knochenheilung in Abhängigkeit von der Defektgrosse [On the healing of bone in relation to the magnitude of the defect]. Helv Chir Acta 39: 409411.

Kadler KE, Holmes DF, Trotter JA, Chapman JA(1996) Collagen fibril formation. Biochem J 316: 1-11.

Koch H (1924) Experimentelle studien uber Knochenregeneration und knochencallusbildung [Experimental studies on bone regeneration and callus formation]. Bruns Beitr Klin Chir 132: 364-440.

Kojimoto H, Yasui N, Goto T, Matsuda S, Shimomura Y (1988) Bone lengthening in rabbits by callus distraction. The role of periosteum and endosteum. J Bone Joint Surg [Br] 70: 543-549.

Krompecher S (1934) Die Entwicklung der Knochenzellen und die Bildung der Knochengrundsubstanz bei der knorpelig und bindegewbig vorgebildeten sowie der primaren reinen Knochenbildung [The development of bone cells and the formation of the ground substance of bone during bone preformed by cartilage or connective tissue as well as during primary pure bone formation]. Verh Anat Ges 42: 34-53.

Krompecher S (1937) Die Knochenbildung [Bone Formation]. Gustav Fischer, Jena.

Krompecher S (1956) Die Beeinflussbarkeit der Gewebsdifferenzierung der granulierenden Knochenoberflachen insbesondere die der Callusbildung [The possibility to influence tissue differentiation of the granulating bone surfaces, especially those of callus formation]. Langenbecks Arch Klin Chir 281: 472-512.
Kusuzaki K, Kageyama N, Shinjo H, Takeshita H, Murata H, Hashiguchi S, Ashihara T, Hirasawa Y (2000) Development of bone canaliculi during bone repair. Bone 27: 655-659.

McKibbin B (1978) The biology of fracture healing in long bones. J Bone Joint Surg [Br] 60: 150-162.

Modis L (1991) Organization of the Extracellular Matrix: A Polarization Microscopic Approach. CRC Press, Boca Raton, FL, USA.

Muller ME (1978) Bases experimentales et principes de 1'osteosynthese par compression [Experimental basis and principles of osteosynthesis by compression]. Internat Orthop 2: 115-125.

Olerud S, Danckwardt-Lillieström G (1968) Fracture healing in compression osteosynthesis in the dog. J Bone Joint Surg [Br] 50: 844-851.

Owan I, Burr DB, Turner CH, Qui J, Tu Y, Onga JE, Duncan RL (1997) Mechanotransduction in bone: osteoblasts are more responsive to fluid flow than mechanical strain. Am J Physiol 273: C810-815.

Palumbo C, Palazinni S, Marotti G (1990a) Morphological study of intercellular junctions during osteocyte differentiation. Bone 11: 401-406.

Palumbo C, Palazinni S, Zaffe D, Marotti G (1990b) Osteocyte differentiation in the tibia of newborn rabbit: an ultrastructural study of the formation of cytoplasmic processes. Acta Anat 137: 350-358.

Pauwels F (1976) Biomechanics of the Normal and Diseased Hip. Theoretical foundation, technique and results of treatment. An atlas. (RJ Furlong, P Maquet, transl.). Springer-Verlag, Berlin, Heidelberg, New York.

Peltonen JI, Kahri AI, Lindberg L-A, Heikkila PS, Karaharju EO, Aalto KA (1992) Bone formation after distraction osteotomy of the radius in the sheep. Acta Orthop Scand 63: 599-603.

Perren SM, Russenberger M, Steinemann S, Muller ME, Allgower M (1969) The reaction of cortical bone to compression. Acta Orthop Scand. Supp 125: 19-30.

Perren SM (1979) Physical and biological aspects of fracture healing with special reference to internal fixation. Clin Orthop Rel Res 138: 175-196.

Perren SM (2002) Evolution of the internal fixation of long bone fractures. The scientific basis of biological internal fixation: Choosing a balance between stability and biology. J Bone Joint Surg [Br] 84: 1093-1110.

Petersen H (1930) Die Organe der Skelettystems. In: Handbuch der Mikroskopischen Anatomie des Menschen [The organs of the skeletal system. In. The Manual of Human Microscopic Anatomy] (von Mollendorff W, ed). Volume 2, part 2: pp 520-678. Julius Springer, Berlin.

Prendergast PJ, van der Meulen MCH (2001) Mechanics of bone regeneration. In: Bone Mechanics Handbook, second edition (SJ Cowin, ed), pp 32.1-32.13, CRC Press, Boca Raton, FL.

Rhinelander FW (1968) The normal microcirculation of diaphyseal cortex and its response to fracture. J Bone Joint Surg [Am] 50: 784-800.

Rivas R, Shapiro F (2002) Structural stages in the development of the long bones and epiphyses: a study in the New Zealand rabbit. J Bone Joint Surg [Am] 84: 85100 . 
Roach HI (1992) Trans-differentiation of hypertrophic chondrocytes into cells capable of producing a mineralized matrix. Bone Miner 19: 1-20.

Roux W (1912) Anpassungslehre, Histomechanik, Histochemie. Mit Bemerkunngen uber die Entwicklung und Formgestaltung der Gelenke [Adaptation, Histomechanics, Histochemistry. With Comments on the Development and Morphology of the Joints]. Virchows Arch 207: 168-209

Rubinacci A, Covini M, Bisogni C, Villa I, Galli M, Palumbo C, Ferretti M, Muglia MA, Marotti G (2002) Bone as an ion exchange system: evidence for a link between mechanotransduction and metabolic needs. Am J Physiol Endocrinol Metab 282: 851-864.

Schenk R, Willenegger H (1964) Zur histologie der primaren knochenheilung [The histology of primary bone repair]. Langenbecks Arch Klin Chir 308: 440-452.

Schenk R, Willenegger H (1967) Morphological findings in primary fracture healing. Symp Biol Hung 7: 75-86.

Schenk R, Willenegger H (1977) Zur histologie der primaren knochenheilung [The histology of primary bone repair]. Unfallheilkunde 80: 155-160.

Schenk RK, Hunziker EB (1994) Histologic and ultrastructural features of fracture healing. In: Bone Formation and Repair (Brighton CT, Friedlaender GE, Lane JM, eds) American Academy of Orthopaedic Surgeons, Rosemont, IL. pp. 117-146.

Shapiro F, Holtrop ME, Glimcher MJ (1977) Organization and cellular biology of the perichondrial ossification groove of Ranvier. J Bone Joint Surg [Am] 59: 703-723.

Shapiro F (1988) Cortical bone repair. The relationship of the lacunar-canalicular system and intercellular gap junctions to the repair process. J Bone Joint Surg [Am] 70: 1067-1081.

Shapiro F, Cahill C, Malatantis G, Nayak RC (1995) Transmission electron microscopic demonstration of vimentin in rat osteoblast and osteocyte cell bodies and processes using the immunogold technique. Anat Rec 241: 39-48.

Shapiro F (1997) Variable conformation of gap junctions linking bone cells: a transmission electron microscopic study of linear, stacked linear, curvilinear, oval and annular junctions. Calcif Tissue Int 61: 285-293.

Shapiro F (1998) Epiphyseal and physeal cartilage vascularization: a light microscopic and autoradiographic study of cartilage canals in newborn and young postnatal rabbit bone. Anat Rec 252: 140148 .

Smith JW (1960a) The arrangement of collagen fibres in human secondary osteones. J Bone Joint Surg [Br] 42: 588-605.
Smith JW (1960b) Collagen fibre patterns in mammalian bone. J Anat 94: 329-344.

Trueta J, Morgan JD (1960) The vascular contribution to osteogenesis. I. Studies by the injection method. J Bone Joint Surg [Br] 42: 97-109.

Uhthoff HK, Rahn BA (1981) Healing patterns of metaphyseal fractures. Clin Orthop Rel Res 160: 295-303.

Urist MB, Johnson RW Jr (1943) Calcification and ossification. IV. The healing of fractures in man under clinical conditions. J Bone Joint Surg 25: 375-426.

Vortkamp A, Pathi S, Peretti GM, Caruso EM, Zaleske DJ, Tabin CJ (1998) Recapitulation of signals regulating embryonic bone formation during postnatal growth and in fracture repair. Mech Dev 71: 65-76.

Wagermaier W, Gupta HS, Gourrier A, Burghammer M, Roschger P, Fratzl P (2006) Spiral twisting of fiber orientation inside bone lamellae. Biointerphases 1: 1-5.

Wehner E (1921) Experimentelle Studie über die Knochencallusentwicklung unter dem Einflusse des funktionellen Reizes ohne und mit besonderer Schädigung von Periost und Knochenmark [Experimental study on the development of bone callus under the influence of the functional stimulation without and with special damage to periosteum and bone marrow]. Bruns Beitr Klin Chir 123: $541-583$.

Weidenreich F (1930) Das Knochengewebe. In: Handbuch der Mikroskopischen Anatomie des Menschen [Bone Tissue. In: Manual of Human Microscopic Anatomy] (von Mollendorff W, ed). Volume 2, part 2, pp. 391-520. Julius Springer, Berlin.

Weinans H, Prendergast PJ (1996) Tissue adaptation as a dynamical process far from equilibrium. Bone 19: 143-149.

Weiner S, Arad T, Sabanay I, Traub W (1997) Rotated plywood structure of primary lamellar bone in the rat: orientations of the collagen fibril array. Bone 20: 509-514.

Wiedemann M (1996) Callus distraction: a new method? Clin Orthop Rel Res 327: 291-304.

Wieder H (1907) Regeneration of bone. An essay, illustrated by photographs and photomicrographs, dealing with the repair of simple fractures and the regeneration of bone after partial injury and subperiosteal resection. Univ Pennsylvania Med Bull 20: 109-138.

Wolff J (1892) Das Gesetz der Transformation der Knochen. Berlin: A Hirschwald. [English translation: The Law of Bone Remodelling. (P Maquet, R. Furlong, transl). Berlin, Heidelberg, New York, 1976.]

Yasui N, Sato M, Ochi T, Kimura T, Kawahata H, Kitamura Y, Nomura S (1997) Three modes of ossification during distraction osteogenesis in the rat. J Bone Joint Surg [Br] 79: 824-830. 